\title{
A Description of a 1260-Year Control Integration with the Coupled ECHAM1/LSG General Circulation Model
}

\author{
JIN-SONG VON STORCH \\ Institute of Meteorology, University of Hamburg, Hamburg, Germany \\ VIATCHESLAV V. KHARIN \\ Canadian Centre for Climate Modeling and Analysis, University of Victoria, Victoria, British Columbia, Canada \\ UlRich CUBASCH \\ German Climate Computer Center, Hamburg, Germany \\ Gabriele C. Hegerl and Dierk Schriever \\ Max-Planck Institute for Meteorology, Hamburg, Germany \\ HANS VON STORCH AND EdUARDo ZORITA \\ Institute of Hydrophysics, GKSS Research Center, Geesthacht, Germany
}

(Manuscript received 17 May 1996, in final form 2 October 1996)

\section{ABSTRACT}

\begin{abstract}
A 1260-yr integration generated by the ECHAM1/LSG (Large Scale Geostrophic) coupled atmosphere-ocean general circulation model is analyzed in this paper. The analysis focuses on the climate drift and on the variations of the coupled atmosphere-ocean system after the initial climate drift has essentially died out.

The initial drift is induced, to a large extent, by the applied heat flux correction, which has very large spatially fixed values of upward heat flux in the polar regions, in particular along the Antarctic coast. The globally integrated freshwater flux becomes unbalanced during the integration, due to the changes in the snow accumulation rate over Greenland and Antarctica. The resulting net upward freshwater flux induces a linear trend in the salinity of the upper ocean. The drift of temperature and salinity in the deep ocean, which is essentially independent of the boundary condition variations during the coupled integration, is presumably related to the spinup of the deep ocean prior to the coupling.

The analysis of the last $810 \mathrm{yr}$ of the integration, which is free from the strong initial drift, suggests that the tropospheric variations are white on timescales longer than 1 yr. The dominant Northern Hemispheric mode resembles the western Atlantic pattern. The dominant tropical and Southern Hemispheric modes are essentially zonally symmetric. All these modes can be found on both short $(1 \mathrm{yr})$ and long $(15 \mathrm{yr})$ timescales. For the oceanic variations, the spatial distribution of the total variance and the dominant modes and the relationships between these modes are studied. For the horizontal barotropic streamfunction, the most dominant mode describes an anomalous westward (eastward) circumpolar flow together with clockwise (anticlockwise) circulation in the Southern Atlantic and southeast of South Africa and in the Southern Pacific. For the zonally averaged meridional circulations the most dominant modes of variability describe essentially recirculations within each basin.
\end{abstract}

\section{Introduction}

One way to study the climate system is to perform numerical experiments using a general circulation model (GCM). An analysis of the output of the experiments

Corresponding author address: Jin-Song von Storch, Institute of Hydrophysics, GKSS-Research-Center, P.O. Box D-21502 Geesthacht, Germany.

E-mail: jinsong@gkss.de would indicate what the characteristics of variations of the coupled atmosphere-ocean system are and what the responsible physical mechanisms might be. This approach, however, faces the problem that the model used is not perfect. In fact, a perfect model cannot be designed without a full understanding of the climate system. On the other hand, without a systematic data analysis, it is impossible to know what types of variations the model produces and what problems the model may have. Consequently, to achieve a gradual improvement of our understanding of climate variations, modeling 
activities and model-data studies must be developed side by side.

Following this line, an analysis of a 1260-yr control integration with a low-resolution coupled atmosphereocean GCM is carried out. The integration was performed at the Max-Planck-Institute for Meteorology in Hamburg. Apart from two other millennia coupled integrations performed at Geophysics Fluid Dynamics Laboratory in Princeton (Manabe and Stouffer 1996) and the Hadley Centre in the United Kingdom (Tett et al. 1997), this is one of the three millennia integrations worldwide. There is no doubt that the coupled model considered here is far from perfect. In terms of globally averaged near-surface temperature, a quantity for which observations over a long time period are available, model intercomparison studies showed that the variability generated by the ECHAM1/LSG (Large Scale Geostrophic) model is rather low compared to the variability of observations (Gates et al. 1996; Santer et al. 1996). It is, however, unclear what part of the observed variability is influenced by external forcing absent in the coupled model (e.g., anthropogenic effects, volcanic eruptions, changes in solar radiation). Hegerl et al. (1996) showed that, on timescales of years and decades, the variability generated by the ECHAM1/LSG model is smaller by a factor of about 1.5 to 2 than that of the observations. Disagreement between the coupled models and observations is also found in terms of spatial structures of near-surface temperature (Santer et al. 1995; Kim et al. 1996). Nevertheless, the 1260-yr integration provides us with the first opportunity to consider a new class of questions and to study the coupled atmosphere-ocean system from a different but global point of view. The new class of questions we can ask concerns both oceanic and atmospheric variations.

\section{a. Oceanic variability}

Concerning the oceanic variability, the shortness and the rarity of the available data make a study of the overall variability using observational data almost impossible. Many questions concerning the basic characteristics of the large-scale oceanic variability, in particular those in the deep ocean, are left open.

Bearing the limitations of the observational data in mind, numerical integrations become a promising alternative tool for variability studies. Some efforts have been made using uncoupled ocean general circulation models (OGCMs). The variability in such models appears either in the form of transitions from one climate state to another or in the form of regular or irregular oscillations. Examples of the latter are given, for example, by Yin and Sarachik (1995) and Drijfhout et al. (1996). In these uncoupled experiments, the atmospheric forcing is time independent. The resulting variabilities have a self-sustained character and are described by spectra with sharp spectral peaks. As a consequence of the experimental design, the origin of these variations lies in the dynamics of the OGCM, rather than in the atmospheric forcing. The atmospheric forcing in reality, however, is a function of time. In particular, since the timescale of weather fluctuations is short, the atmospheric forcing can be considered as essentially white at low frequencies. In his concept of stochastic climate models, Hasselmann (1976) pointed out the role of such a forcing in generating the spectra of oceanic variations. He suggested that an ocean model should be forced not only by time-independent fluxes, which have (locally) nonzero time means, but also by time-varying fluxes that have zero time means. Compared to the variations generated by an uncoupled OGCM with time-independent atmospheric forcing, the variations generated by an OGCM with time-varying atmospheric forcing have much smoother spectra, which are consistent with the spectra derived form the few observational data that are available.

One example of using time-varying atmospheric forcing is given by Mikolajewicz and Maier-Reimer (1990). They identified one type of oceanic variation that can be generated by including a randomly fluctuating component into the freshwater flux. This is the first step toward the simulation of more realistic oceanic variations that are expected to be driven by fluctuating forcings in all fluxes. However, further improvement with uncoupled OGCMs is difficult, since fluctuating forcings in all fluxes cannot be obtained without making assumptions about the air-sea interaction processes. Even when uncoupled integrations driven by presentday second moment statistics are possible, one important problem is still open, namely, whether and to what extent oceanic variations will act back on the fluctuating fluxes. That is to say, in order to obtain realistic oceanic variations, an ocean model should be driven by timedependent second moment statistics, which depend on the simultaneous state of the ocean. In this sense, coupled GCMs become the only straightforward tool for studying oceanic variability. Variabilities generated by a coupled ocean-atmosphere general circulation model (AOGCM) should be more realistic than those generated by an uncoupled OGCM.

Following this discussion, the 1260 -yr integration is considered as a dynamically consistent representation for the oceanic variations. We will limit ourselves to the global description of these variations. Since little is known in this respect, we start with basic questions, such as what is the spatial distribution of oceanic variations, what are the most dominant large-scale modes of the variations, and to what extent are variations of different parts of the oceanic circulation related to each other. The analysis is carried out from a global point of view. Regional aspects of this and other millennia integrations can be found in Delworth et al. (1993), von Storch (1994), Robertson (1996), and Zorita and Frankignoul (1997). 


\section{b. Atmospheric variability}

The situation is different for the atmospheric variations. Observed global data representing the entire troposphere are available for a few decades. Up to timescales that can be resolved from the observational records, the spatial distribution of atmospheric variations are well documented (e.g., Blackmon 1976; Blackmon et al. 1984; Rogers and van Loon 1982). For instance, Blackmon et al. summarized the differences between the spatial distributions of variations on synoptic timescales and on timescales longer than 10 days. These differences indicate that the mechanisms behind these two types of variations are different. However, because of the shortness of the observational records, it is not clear whether the spatial distribution of variations on timescales around a year remain unchanged for variations on timescales, say, longer than $15 \mathrm{yr}$. The answer to this question may indicate whether there exist atmospheric processes that operate on long timescales. A related question is to what extent are the atmospheric variations white. The millennia integration generated by a coupled AOGCM provides the first opportunity to study these questions.

Even though the millennia integration with the coupled ECHAM1/LSG model opens a new horizon, the results derived from the integration can be considered only as the present-day best guess of the answers to the questions addressed above. One must be aware of the limited resolution and simplified physics of the model, as well as the problems caused by the flux corrections. A description of the coupled model design is given in section 2. To give the reader an idea about the model performance, a complete view of the evolution of the atmosphere, ocean, and sea ice during the whole integration, as well as the mean state, is discussed in sections 3 and 4. Since the strong initial drift may disguise the true variability of the coupled system, the oceanic and atmospheric variations are studied in section 5 using the last $810 \mathrm{yr}$ of the integration. The analysis results are summarized in section 6 .

\section{Model description}

The climate model used in this study is the coupled global ocean-atmosphere model described by Cubasch et al. (1992). Its atmospheric component is the spectral ECHAM1 model, which is based on a low-resolution version of the ECMWF numerical weather prediction model modified for climate applications (Roeckner et al. 1992). Prognostic variables are vorticity and divergence (representing the horizontal wind), temperature, surface pressure, water vapor, and cloud water (liquid or frozen). Subgrid-scale processes such as radiation (including the diurnal cycle), cloud formation, precipitation, convection, turbulent mixing, gravity wave drag, and soil processes are parameterized. The calving of glaciers is not parameterized in the model. An attempt is made to correct the error caused by the accumulation of snow over glaciers using the flux correction for freshwater flux.

In the present study, the horizontal resolution of the atmosphere model is limited by a triangular truncation at total wavenumber 21 . The nonlinear advection terms and the physical processes are calculated on a Gaussian grid with resolution roughly $5.6^{\circ} \times 5.6^{\circ}$. In the vertical, the model is discretized on 19 levels in a hybrid $\sigma-p$ coordinate system. The time integration is semi-implicit with a time step of $40 \mathrm{~min}$.

The ocean general circulation model used is the LSG model (Maier-Reimer and Mikolajewicz 1991; MaierReimer et al. 1993), which is based on the primitive equations appropriate for large-scale geostrophic motion. The nonlinear advection of momentum is neglected, and fast gravity waves are strongly damped by an implicit time integration scheme, which uses a time step of 30 days. Salinity and temperature transport are computed with an upstream advection scheme. A small explicit horizontal diffusion of $2 \times 10^{2} \mathrm{~m}^{2} \mathrm{~s}^{-1}$ and a moderate viscosity of about $5 \times 10^{4} \mathrm{~m}^{2} \mathrm{~s}^{-1}$ are introduced to counteract the inherent tendency for mode splitting in the $\mathrm{E}$ grid used in the horizontal discretization scheme. Vertical convective mixing becomes active whenever the stratification becomes unstable (mainly in high latitudes, where strong surface cooling occurs). Sea ice is produced whenever the heat loss to the atmosphere would lead the water temperature to fall below the freezing point (Maier-Reimer et al. 1993).

In the present simulation, the discretization of the ocean model is based on 11 unevenly spaced vertical levels and an E grid with an effective grid size of $4^{\circ}$. Note that the ocean model used in this integration, both during the spinup and in the coupled mode, is not the standard LSG version described in Mikolajewicz and Maier-Reimer (1990) and Maier-Reimer et al. (1993). To match the T21 resolution, a coarser grid is chosen, so that both the resolution and the topography of this run differs from those of the standard LSG model. Because of these differences, it is hard to make a detailed comparison between the time-mean state of the coupled model and that obtained from the standard version used in the uncoupled experiments.

In the coupled model integration, the basic ocean time step of 30 days is reduced to 1 day for the computation of sea ice and of temperature and salinity in the two uppermost ocean levels in order to resolve the response of the upper ocean to the synoptic variability of the atmosphere.

Before the coupling, the ocean model was integrated for $7000 \mathrm{yr}$. The first $5000 \mathrm{yr}$ of this run were driven by the monthly climatological wind stress fields of Hellerman and Rosenstein (1983), and a feedback to an effective monthly mean air temperature constructed from the COADS (Woodruff et al. 1987) and the annual-mean surface salinity from Levitus (1982). The last $2000 \mathrm{yr}$ were driven by the freshwater fluxes, which were di- 
agnosed from the first $5000 \mathrm{yr}$, and the same wind stress and air temperature forcing as used before. The final state of this integration was then coupled to the ECHAM1 model.

The ocean and atmosphere components are coupled by the air-sea fluxes of momentum, heat (sensible, latent, and radiative), and freshwater (precipitation minus evaporation, plus runoff along the coastal boundaries). These fluxes are calculated by the atmospheric model using the sea surface temperature and the sea ice thickness as surface boundary conditions. To avoid an unrealistic climate drift of the coupled system, a flux correction is applied (Sausen et al. 1988). This is equivalent to coupling the ocean and atmosphere by the anomalies of the fluxes relative to the equilibrium states of the ocean and atmosphere models as found in separate uncoupled control simulations. Both models are integrated synchronously, but with their respective time step. Thus, the fluxes computed at each 40-min time step by the atmospheric model are accumulated over the ocean time step and then transferred to the ocean model.

This coupled model has been used successfully in a number of climate change experiments (Bakan et al. 1991; Cubasch et al. 1992, Cubasch et al. 1994, Cubasch et al. 1995). Its flux correction terms and its performance have been compared with those in other coupled atmosphere-ocean GCMs in Gates et al. (1993) and in IPCC (1992).

\section{Time evolution of the coupled system}

This section deals with questions of how the states of the atmosphere, sea ice, and ocean evolve in time, and whether the coupled system has reached an equilibrium state after a 1260-yr integration. Several reasons that might contribute to the behaviors of the climate drift are discussed. The evolution of each subsystem is described by area-averaged variables and some oceanic indices.

\section{a. Evolution of sea ice}

The sea ice in the coupled integration exhibits significant variations and reaches, after about $450 \mathrm{yr}$, a new equilibrium that is quite different from the initial sea ice distribution. Figure 1 shows the annual time series of sea ice calculated separately for the Northern and Southern Hemispheres.

Sea ice volume grows rapidly in the first 70-80 yr both in the Northern and Southern Hemispheres (Fig. 1a). In the Northern Hemisphere, the initial value of sea ice volume of about $1 \times 10^{4} \mathrm{~km}^{3}$ increases up to $4 \times$ $10^{4} \mathrm{~km}^{3}$. For comparison, the estimate of present-day Arctic sea ice volume is $2 \times 10^{4} \mathrm{~km}^{3}$ (e.g., Untersteiner 1984). In the corresponding period in the Southern Hemisphere, annual sea ice volume grows from $3 \times 10^{4}$ $\mathrm{km}^{3}$ to about $8 \times 10^{4} \mathrm{~km}^{3}$. Estimated present-day annual range of Antarctic sea ice volume is between $5 \times 10^{3}$ $\mathrm{km}^{3}$ and $5 \times 10^{4} \mathrm{~km}^{3}$. In the following period, sea ice volume in the Northern Hemisphere remains at near the same level, whereas in the Southern Hemisphere it goes down to about $5 \times 10^{3} \mathrm{~km}^{3}$ during the following 300 yr and remains afterward at this very low level.

Sea ice cover (Fig. 1b) increases in the Northern Hemisphere in the first few decades from $10 \times 10^{6} \mathrm{~km}^{2}$ up to $12 \times 10^{6} \mathrm{~km}^{2}$. Estimated annual range of Arctic sea ice cover in the present climate are about $6 \times 10^{6}$ $-14 \times 10^{6} \mathrm{~km}^{2}$. Average sea ice thickness, computed as the ratio of sea ice volume over sea ice cover, grows from roughly $1 \mathrm{~m}$ at the beginning of the integration to about $3 \mathrm{~m}$ after $100 \mathrm{yr}$. In the Southern Hemisphere, annual sea ice cover varies about the value of $14 \times 10^{6}$ $\mathrm{km}^{2}$ in the first $100 \mathrm{yr}$. For comparison, the present-day seasonal variations of this quantity are $2 \times 10^{6}-15$ $\times 10^{6} \mathrm{~km}^{2}$. Sea ice becomes thicker, reaching an average thickness of about $5 \mathrm{~m}$ in the years 70-80, compared to $1.5 \mathrm{~m}$ in the first year. In the following 200-300 $\mathrm{yr}$ a significant reduction of the sea ice cover happens. After about $450 \mathrm{yr}$ from the beginning of the coupled integration, the sea ice component in the Southern
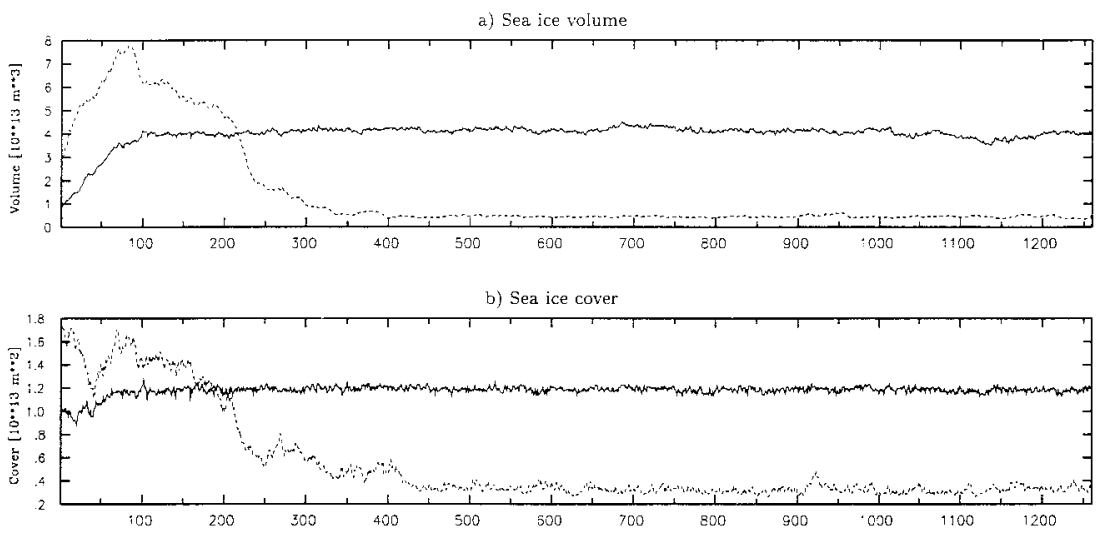

FIG. 1. Annual time series of sea ice volume (a) (in $10^{13} \mathrm{~m}^{3}$ ) and sea ice cover (b) (in $10^{13}$ $\mathrm{m}^{2}$ ) in the Northern Hemisphere (solid lines) and in the Southern Hemisphere (dotted lines). 

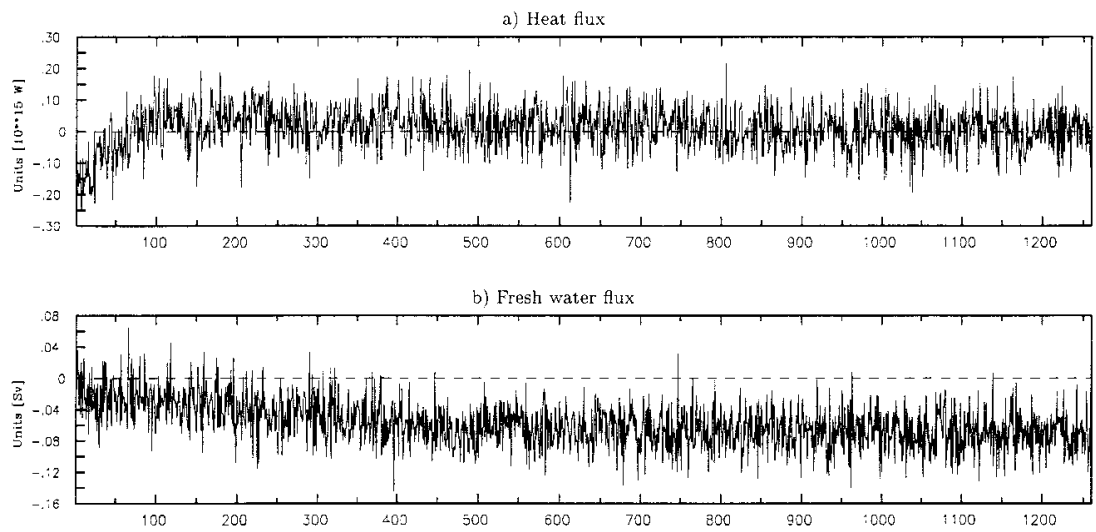

FIG. 2. Annual time series of globally integrated fluxes of heat (a) (in PW) and freshwater (b) (in Sv) over ocean. The fluxes are the sum of the model fluxes and the flux corrections. Positive values indicate downward fluxes from the atmosphere into the ocean.

Hemisphere reaches near stable equilibrium with a sea ice cover of about $3 \times 10^{6} \mathrm{~km}^{2}$ and an average thickness of about $1.2 \mathrm{~m}$.

To understand the cause of the drift, the downward heat flux at the air-sea interface is considered. Since the model sea ice is purely thermodynamically driven [for a detailed description see Maier-Reimer et al. (1993)], the heat flux plays an important role for the growth of the sea ice.

Figure 2 a shows the evolution of the heat flux (model flux plus heat flux correction) integrated over the whole ocean area. This is the total downward heat flux forcing for the sea ice and oceans. There is a net loss of heat to the atmosphere at the beginning of the integration. However, this global heat loss is only capable of producing the initial growth of sea ice, when it is related to a heat loss from the ocean in the polar regions. To clarify this issue, the spatial distribution of the downward heat flux averaged over the first $10 \mathrm{yr}$ is shown in Fig. 3. Extremely large negative values up to 100$150 \mathrm{Wm}^{-2}$, which indicate net heat loss from the ocean to the atmosphere, are found in the polar regions, in particular along the Antarctic coast. This fact suggests that the initial growth of sea ice is likely caused by the large upward heat flux in the polar regions.

A comparison of Fig. 3 with the distribution of the heat flux correction (Gates et al. 1993) shows that the extreme values in the polar regions stem from the applied heat flux correction. The spatially fixed heat flux correction becomes inconsistent as the sea ice distribution in the model varies. In the presence of large upward heat flux, this mismatch might lead to an initial drift in sea ice, in particular, if the amplitudes of the correction terms are large in the polar region, as is the case in ECHAM1/LSG model.

Since the large values of heat flux correction are found over a much larger area in the Southern Hemisphere than in the Northern Hemisphere, the spatially fixed heat flux correction might also cause different degrees of mismatch in the two hemispheres, and therefore the different behaviors of the sea ice in the north and south polar regions. Apparently, the new state of the coupled system after about $100 \mathrm{yr}$ with more sea ice in the Southern Hemisphere is not stable enough to main-

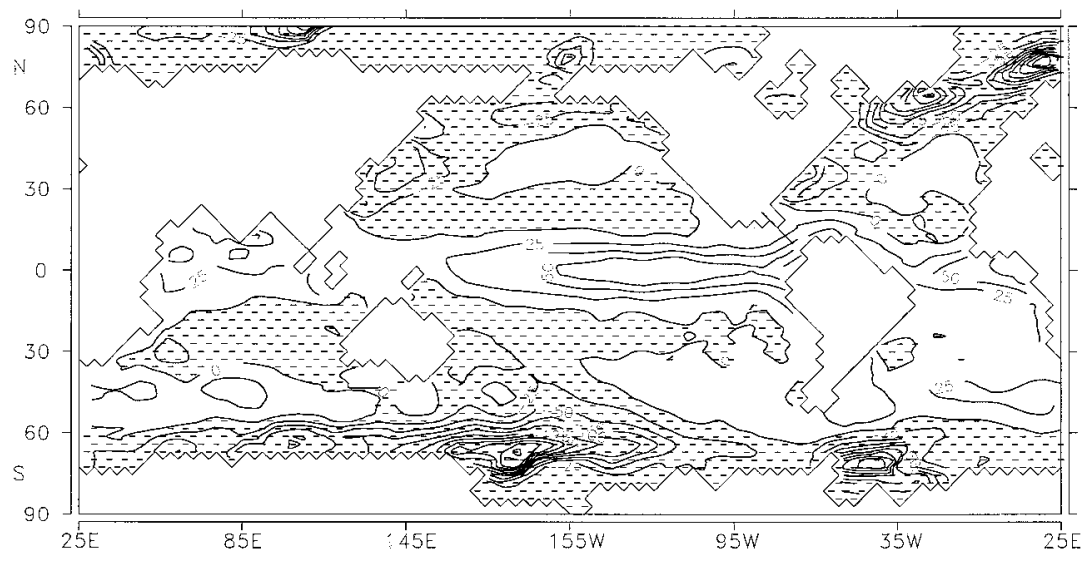

FIG. 3. Spatial distribution of the total heat flux (model heat flux plus heat flux correction) averaged over the first $10 \mathrm{yr}$ in $\mathrm{W} \mathrm{m}^{-2}$. Shaded areas indicate upward heat fluxes. 


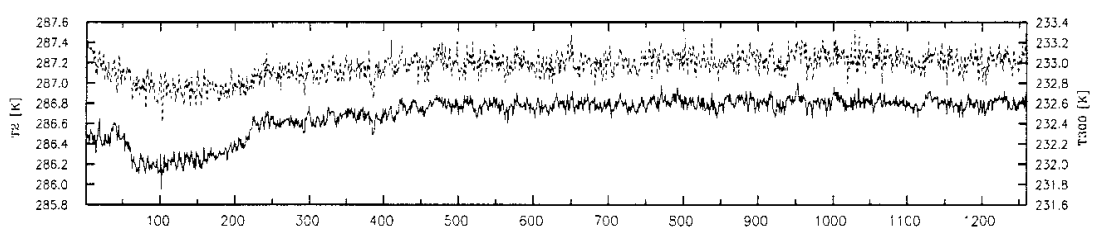

FIG. 4. Annual time series of globally averaged 2-m air temperature (T2, solid line) and 300-hPa temperature (T300, dashed line).

tain sea ice volume on the high level when the global heat flux into the ocean increases after about $100 \mathrm{yr}$ (see Fig. 2a). However, a more thorough analysis is required to clarify this issue, which is out of the scope of this paper.

\section{b. Evolution of the atmosphere}

The time evolution of the atmospheric temperature is closely related to the time evolution of the sea ice. Figure 4 shows globally averaged annual 2-m (solid line) and 300-hPa air temperature (dashed line). Apart from the first 30-40 yr, the globally averaged temperature of the upper troposphere develops parallel to the 2-m temperature. The initial global cooling is halted after $80 \mathrm{yr}$ and is followed by a very slow warming trend in the next few centuries and a quasi-stationary behavior in the last part of integration. The increase and decrease of the temperature corresponds essentially to the decay and growth of the sea ice volume in the Southern Hemisphere shown in Fig. 1a.

To understand how the drift in the global mean temperature is related to the local evolutions, Hovmöller diagrams of the zonally averaged anomalies, as derived by subtracting the 1260-yr means, are shown in Fig. 5.

Figure 5a suggests that the strong drift observed in the
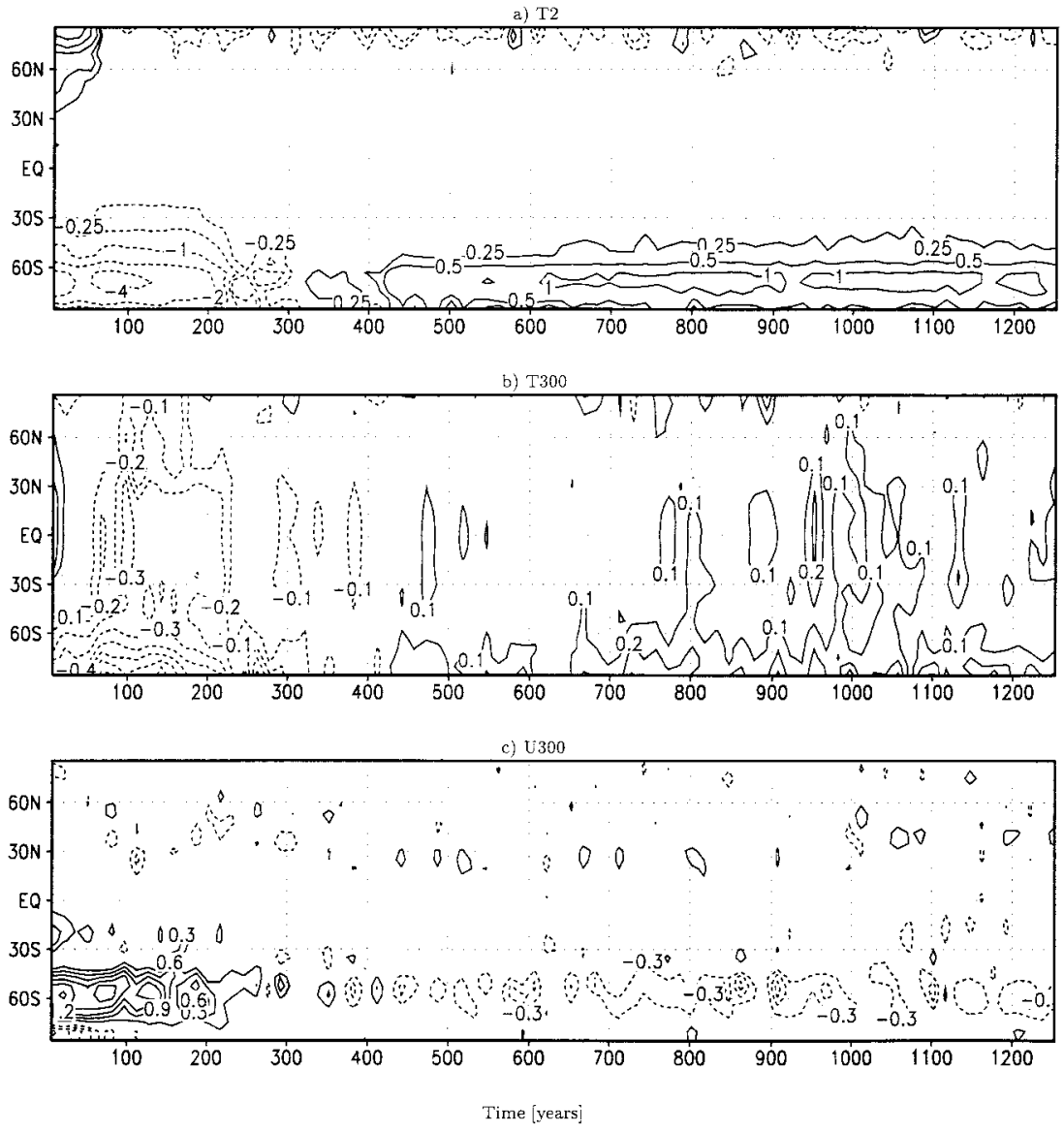

FIG. 5. Hovmöller diagram of 15-yr zonally averaged anomalies: (a) 2-m air temperature T2 (contour values are $-4,-2,-1,-0.5,-0.25,0.25,0.5,1,2 \mathrm{~K}$ ); (b) air temperature at $300 \mathrm{hPa} \mathrm{T} 300$ (contour interval is $0.1 \mathrm{~K}$ ); (c) zonal wind at $300 \mathrm{hPa}$ (contour interval is 0.5 $\mathrm{m} \mathrm{s}^{-1}$ ). Zero lines, which represent 1260 -yr averages, are not shown. 

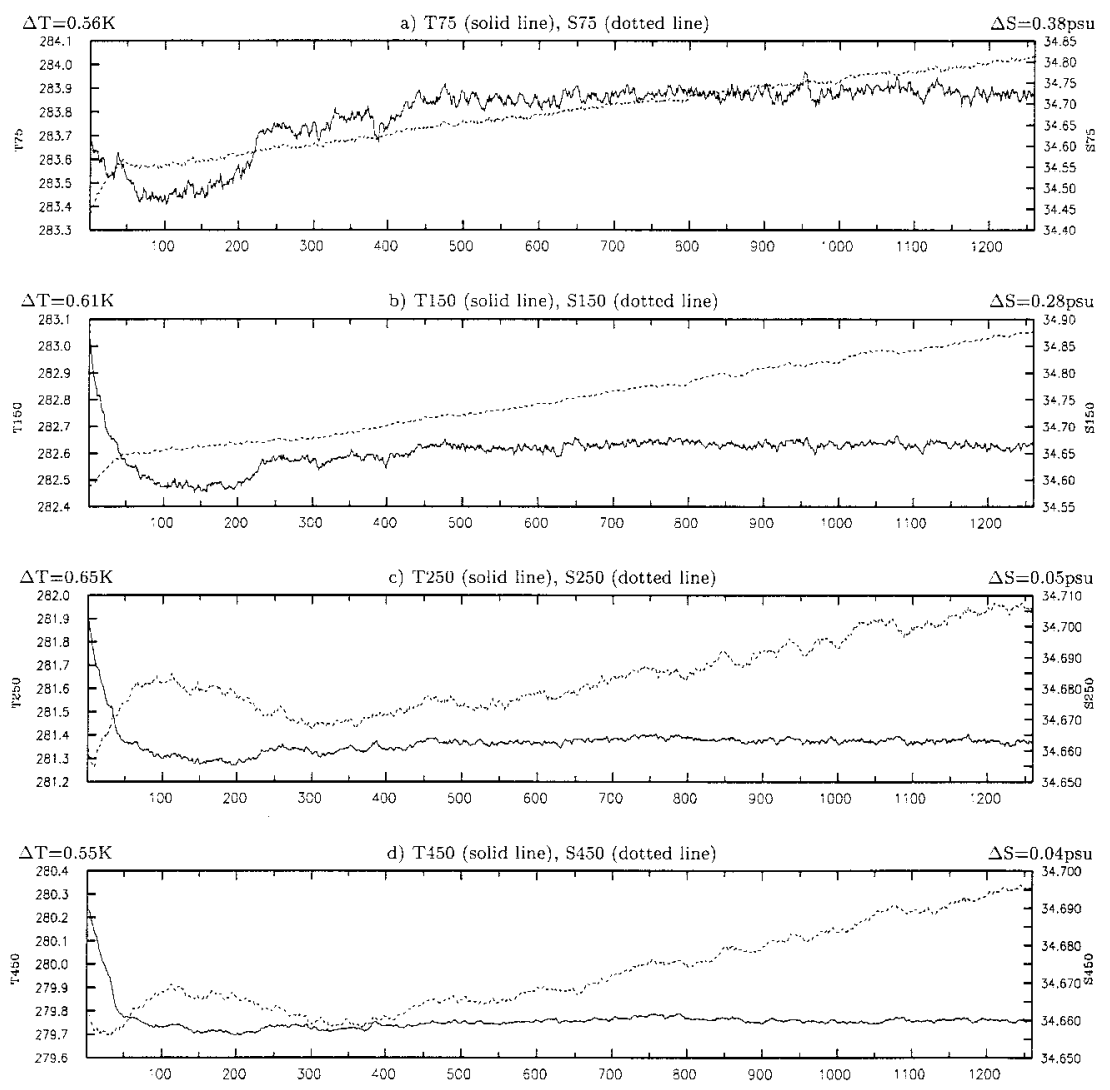

FIG. 6. Annual time series of globally averaged temperature (solid line; in Kelvin) and salinity (dotted line, in psu) in the 75-, 150-, 250-, and 450-m depth. Here, $\Delta \mathrm{T}$ and $\Delta \mathrm{S}$ represent the difference between the minimal and the maximal values.

globally averaged 2-m temperature in Fig. 4a is confined to polar latitudes. The temperature values in the first few decades result basically from relatively warmer northern high latitudes and relatively cooler southern high latitudes. The abrupt cooling in globally averaged $2-\mathrm{m}$ temperature in years 60-70 is essentially induced by the abrupt cooling in the Northern Hemispheric polar regions. The subsequent slow global warming stems from the slow warming in the Southern Hemisphere. Around the Antarctic, the zonally averaged 2-m temperatures are up to $4-5 \mathrm{~K}$ colder at the beginning of the integration than at the end. The temperature anomalies in the Southern Hemisphere spread out from the polar areas into the Tropics. However, since the amplitudes of the tropical anomalies are much smaller than those in the polar regions, they cannot be seen in Fig. 5a.

In the upper troposphere (Fig. 5b), the amplitudes of the temperature anomalies is much smaller. The drift in in the Tropics becomes comparable to that in the polar region. Overall, the troposphere is about a few tenths of a kelvin colder in years 50-150 than in the last part of the integration.

The drift of the near-surface temperature in the Southern Hemispheric polar regions results in a drift in the meridional temperature gradient with its maximum at about $60^{\circ} \mathrm{S}$. Following the thermal wind relation, this in turn leads to the drift in the zonal circulation at $60^{\circ} \mathrm{S}$. The zonally averaged zonal wind at $60^{\circ} \mathrm{S}$ is stronger in the first 2-3 centuries than in the middle and end of the run (Fig. 5c). The maximal decrease of the zonal wind amplitude is about $1 \mathrm{~m} \mathrm{~s}^{-1}$ along $60^{\circ} \mathrm{S}$.

\section{c. Evolution of the ocean}

Figures 6 and 7 show the globally averaged temperature and salinity in seven model layers. The ranges of temperature and salinity changes within $1260 \mathrm{yr}$, computed as the difference between the maximal and minimal values, $\Delta \mathrm{T}$ and $\Delta \mathrm{S}$, are listed to the left and right of the corresponding time series. Both the temperature and the salinity range $\Delta \mathrm{T}$ and $\Delta \mathrm{S}$ have their smallest values at about $1000-\mathrm{m}$ depth. Below and above 1000 $\mathrm{m}, \Delta \mathrm{T}$ and $\Delta \mathrm{S}$ increase with the increasing and decreasing depth. This behavior indicates that the evolution of the thermohaline state in the first $1000 \mathrm{~m}$ is different from that in the deep ocean below $1000 \mathrm{~m}$.

The temperature and salinity in the upper layers appear to be closely coupled to the globally integrated fluxes of heat and freshwater shown in Fig. 2 and the heat-flux-induced changes in sea ice. In the first few 

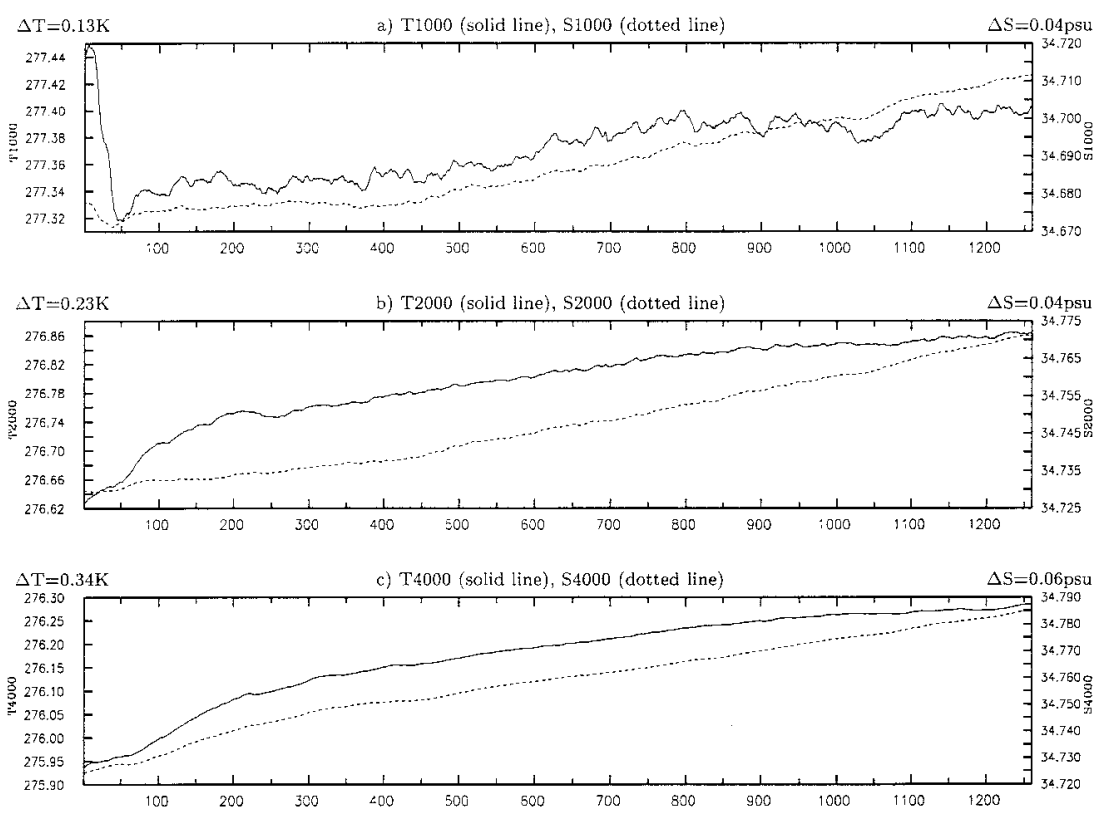

FIG. 7. Annual time series of globally averaged temperature (solid line, in Kelvin) and salinity (dotted line, in psu) in the 1000-, 2000-, and 4000-m depth. Here, $\Delta \mathrm{T}$ and $\Delta \mathrm{S}$ represent the difference between the minimal and the maximal values.

decades, the negative values of the globally integrated heat flux causes the ocean temperature to drop several tenths of a kelvin (solid lines in Fig. 6) and the global sea ice volume to grow about $150 \%$ (Fig. 1a). The increase of sea ice volume causes the upper part of the thermocline to become more saline (dashed lines in Figs. $6 a, b)$.

The globally integrated fluxes of heat and freshwater become stationary after about $300 \mathrm{yr}$ (Fig. 2). The stationary value of the integrated heat flux is essentially zero, but that of freshwater is around $-0.05 \mathrm{~Sv}$. These quasi-stationary fluxes determine the evolution of temperature and salinity of the upper ocean in the last 800 yr. The negative freshwater flux results in a linear trend in salinity with an amplitude of about 0.03 psu century ${ }^{-1}$ at the 75-m and 150-m depth (dashed lines in Figs. 6a,b), whereas the zero heat flux results in a stationary globally averaged temperature (solid lines in Figs. 6a-d).

To understand how the negative values of the globally integrated freshwater fluxes come about, different components that contribute to the freshwater flux are considered. The globally (land and ocean) averaged rate of evaporation minus precipitation $\mathrm{E}-\mathrm{P}$ (not shown) is essentially stationary throughout the whole integration. In contrast, the globally averaged snow depth change (i.e., the first time derivative of the snow depth) increases significantly in the first 300-400 yr, which indicates the increased rate of the snow accumulation (basically over Greenland and Antarctica). The constant rate of $\mathrm{E}-\mathrm{P}$ and the increased rate of snow accumulation result in a reduced runoff to the ocean and, consequently, to the negative freshwater flux to the ocean.
The flux correction that has been designed to take care of the snow accumulation rate works only at the beginning of the integration and cannot correct the imbalance associated with the changes in the snow accumulation rate during the integration.

The situation in the deep ocean (Fig. 7) is different from that in the upper ocean. In contrast to the evolution of the globally integrated heat and freshwater fluxes, which are characterized by an initial drift and a quasistationary behavior afterward (Fig. 2), a nearly constant trend in temperature and salinity is observed throughout the whole integration, in particular in the depth below $1000 \mathrm{~m}$. It appears that the drifts in temperature and salinity are not directly affected by the temporal variations in the boundary fluxes. If they are directly affected by the global fluxes, the time series in Fig. 7 would reveal, in correspondence with Fig. 2, distinctly different evolutions during the initial period and the period afterward. It is possible that the deep ocean has not reached the equilibrium by the time it becomes coupled to the ECHAM1 atmosphere due to some small nonzero globally integrated fluxes used for the uncoupled spinup run. In the coupled integration, these fluxes are not removed and lead to the steady drifts. Since the spinup run has not been stored and is thus unavailable, it is impossible to justify this issue.

The evolution of the dynamical state of the ocean has a quite different nature than that of the thermohaline state. Figure 8 shows the time series of a few indices that characterize the flow field. These are the global mean of the loss of potential energy due to convection, which represents a measure of the strength of deep water 

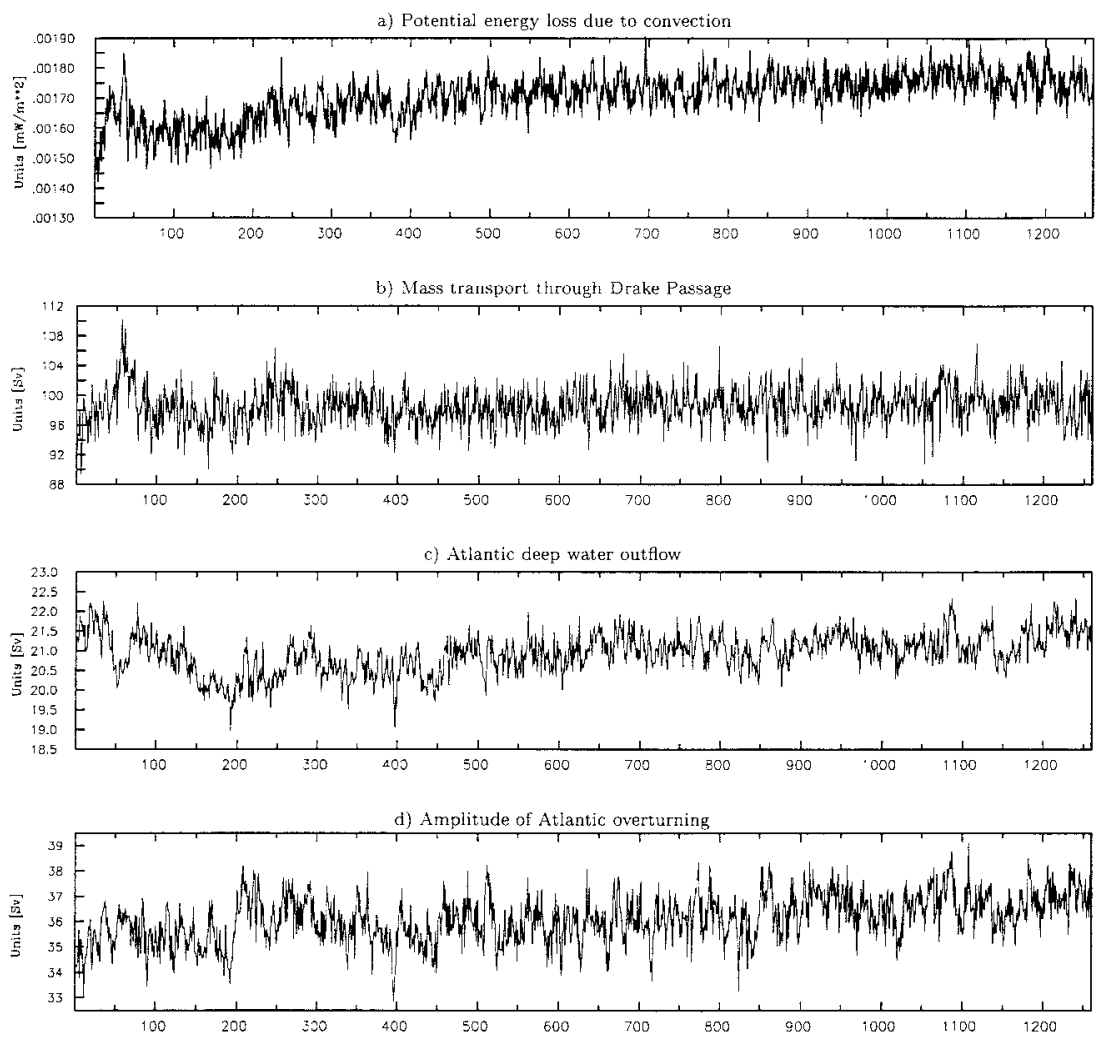

FIG. 8. Annual time series of indices of ocean circulation: (a) the global mean of potential energy dissipation due to convection (in $10^{-3} \mathrm{~W} \mathrm{~m}^{2}$ ); (b) the mass transport through Drake Passage (in Sv); (c) the outflow of the deep Atlantic water at $30^{\circ} \mathrm{S}$ (in Sv); (d) the maximum value of the zonally averaged meridional streamfunction in the North Atlantic (in Sv).

formation (Fig. 8a), the mass transport of the Antarctic Circumpolar Current through Drake Passage (Fig. 8b), the outflow of Atlantic deep water near $30^{\circ} \mathrm{S}$ at about 1500-3500-m depth (Fig. 8c), and the maximum value of the zonally averaged streamfunction in the North Atlantic, which characterizes the Atlantic overturning circulation (Fig. 8d). There are signs of oscillations during the first few centuries, in particular in Figs. 8a-c, and of negligible drifts in the following time period. The oscillations are settled down after about two to three hundred years.

We can conclude that, first, the globally integrated fluxes of heat and freshwater play an important role in the evolutions of the temperature and salinity of the upper ocean, the total volume of sea ice, and the atmospheric temperature, whereas the deep ocean is much less influenced by the variations in the fluxes during the integration. Our analysis suggests that the initial imbalance in the globally integrated heat flux is related to the heat flux correction, which has very large values of about $100-150 \mathrm{~W} \mathrm{~m}^{-2}$ in the polar regions, in particular along the Antarctic coast, whereas the imbalance in the globally integrated freshwater flux is essentially caused by an unbalanced runoff induced by the changed rate of the snow accumulation over Greenland and Antarctica.
Second, apart from the problems with the fluxes, the evolution of the coupled system is also affected by the coupling shock, which may be caused by the switch from fixed fluxes prior to the coupling to the time-varying fluxes after the coupling. The large initial variations of the indices of the oceanic circulation presumably reflect such a coupling shock. In the following, the initial period during which the coupling shock is most pronounced is not included in the analysis of the time-mean state and the variability of the atmosphere-ocean system in the ECHAM1/LSG model. The mean state discussed in section 4 is averaged over the last $810 \mathrm{yr}$ (year 450$1260)$, and the variations discussed in section 5 are derived from the anomalies of the last $810 \mathrm{yr}$ obtained by subtracting the $810-y r$ mean.

\section{Time-mean state}

\section{a. Time-mean oceanic circulation}

The coarse features of the mean circulation in the coupled model are similar to that as obtained from the standard version of the uncoupled LSG model (Mikolajewicz and Maier-Reimer 1990; Maier-Reimer et al. 1993). As far as the detailed structure is concerned, the first-order discrepancies are presumably explained by 

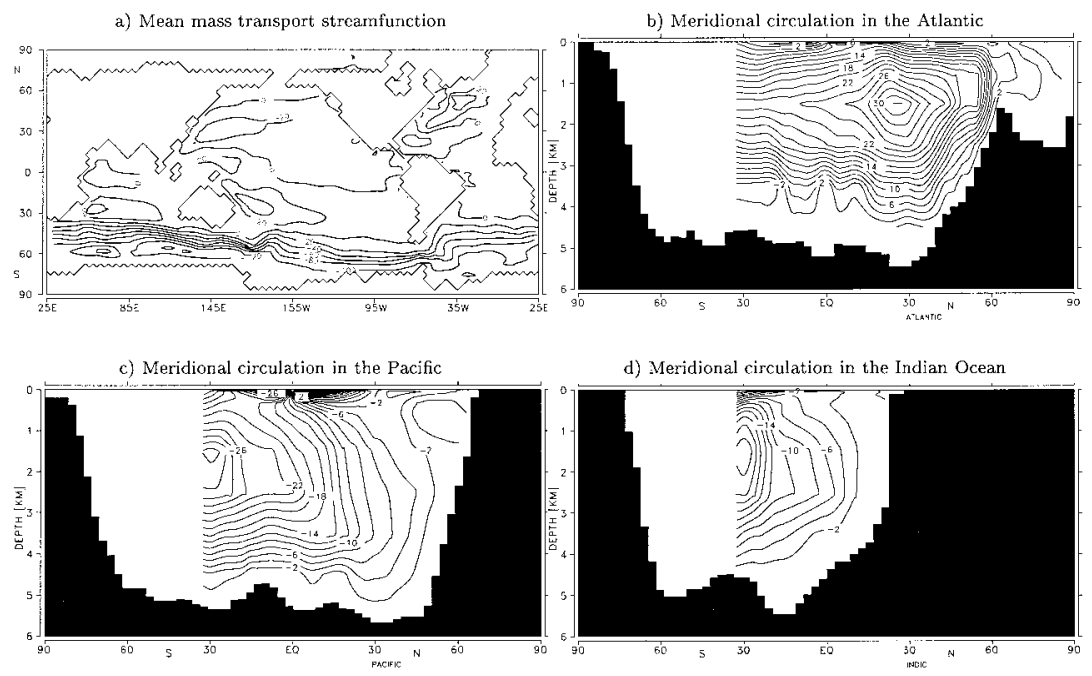

FIG. 9. The last 810-yr (450-1260) mean of the horizontal barotropic streamfunction (a), and of the zonally averaged streamfunction of the meridional circulation in the Atlantic (b), in the Pacific (c), and in the Indian Ocean (d) in Sv. In the regions south of $30^{\circ} \mathrm{S}$, where the longitudinal boundaries are absent, the basin specific streamfunctions are not defined.

the fact that the LSG model in the present integration differs from the standard version in terms of resolution and topography.

The gross features of the mean oceanic circulation are summarized in Fig. 9. The most remarkable feature in the horizontal barotropic circulation (Fig. 9a) is a strong Antarctic Circumpolar Current that produces a mass transport of about $100 \mathrm{~Sv}$ in the Drake Passage. The value of transport is reasonable compared to observations. The mean measured transport through Drake Passage inferred from 3-yr records of pressure gauges is $123 \pm 10 \mathrm{~Sv}$ (Whitworth and Peterson 1985). The Atlantic gyres are located, in correspondence with the low-level atmospheric circulation in the ECHAM1 model, further southward relative to the observations. The general structure of the gyres is simulated reasonably well. But the transports, such as those of the Kuroshio and the Gulf Stream, are underestimated.

The characteristics of the standard "conveyor belt" are reproduced. The Atlantic overturning circulation, as indicated by the zonally averaged streamfunction of the meridional circulation shown in Fig. 9b, is associated with an inflow in the upper $1500 \mathrm{~m}$, an outflow of about $22 \mathrm{~Sv}$ in an intermediate layer in the $1500-3500-\mathrm{m}$ depth, and a weak bottom inflow of about $2 \mathrm{~Sv}$. The maximum value of the meridional streamfunction in the Atlantic is over $30 \mathrm{~Sv}$. The outflow of the Atlantic intermediate water joins the Antarctic Circumpolar Current and forms the deep inflows into both the Pacific (Fig. 9c) and the Indian Ocean (Fig. 9d), which upwells in most parts of the two oceans. The inflow of deep water is more than $20 \mathrm{~Sv}$ in the Pacific and about 16 $\mathrm{Sv}$ in the Indian Ocean.

The patterns just discussed are obtained from the last $810 \mathrm{yr}$. They are visually almost identical to those de- rived from the first $450 \mathrm{yr}$. Regional discrepancies show up when the differences between the two means are calculated. These differences, however, do not substantially alter the gross features of the mean circulation, as already indicated by the circulation indices in Fig. 8 . Thus, the strong drift in sea ice does not cause substantial changes in the gross features of the mean circulation.

\section{b. Time-mean atmospheric circulation}

The distribution of sea level pressure (SLP) in northern winter (December-February) and in northern summer (June-August) averaged over the last $810 \mathrm{yr}$ is shown in Figs. 10a,b. For comparison, climatological distribution of SLP based on the 1986-95 ECMWF analysis is shown in Figs. 10c,d. The Aleutian low during DJF in the model is about $5 \mathrm{hPa}$ deeper than in the observations. The Iceland low is underestimated and shifted about $20^{\circ}$ southward relative to the observed one, causing a southward shift of the Atlantic gyre system. The mean SLP values over the Arctic are up to $15 \mathrm{hPa}$ overestimated during northern winter. These all are the features of the uncoupled ECHAM1 model and can be found in the atmosphere-only run with climatological SST and sea ice as documented by Roeckner et al. (1992). They suggested that the overestimated SLP in high latitudes is caused by an inappropriate parameterization of gravity wave drag in the ECHAM1 model. In northern summer, the model reproduces the observed surface pressure relatively well, with slightly underestimated high pressure systems over the northern oceans.

In the Southern Hemisphere the subtropical highs are about $5 \mathrm{hPa}$ weaker than observed in both seasons and the subpolar lows around Antarctica are $10-20 \mathrm{hPa}$ 

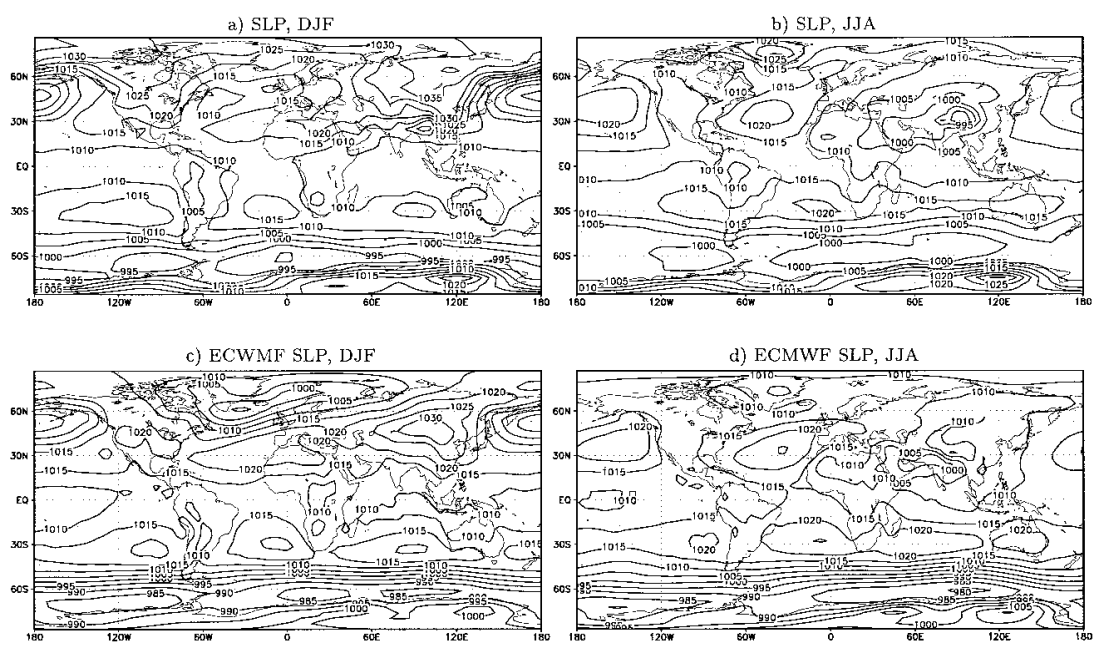

FIG. 10. Mean sea level pressure in northern winter DJF (a) and in northern summer JJA (b) averaged over the last $810 \mathrm{yr}$ of the coupled control run. For comparison, climatological distribution based on ECMWF analysis in 1986-95 are shown in (c) DJF and (d) JJA. Contour interval is $5 \mathrm{hPa}$.

weaker than in the observations. As a result, the meridional pressure gradient in $30^{\circ}-50^{\circ} \mathrm{S}$ in Figs. $10 \mathrm{a}, \mathrm{b}$ is strongly underestimated in the model compared to the present climate. We have two reasons to believe that this model error is not related to the drift in sea ice. First, the sea-ice-induced changes in the meridional pressure gradient, as described in term of the zonal wind in Fig. 5c, are centered at about $60^{\circ} \mathrm{S}$ and therefore much farther south compared to the mean location of the "roaring forties." Second, a much too weak midlatitude pressure gradient is a common feature of many lowresolution atmosphere models driven by climatological SST (Xu et al. 1990). The predecessor of the ECHAM1 model is one of such models. This feature of the Southern Hemispheric circulation has not been improved in the ECHAM1 T21 model (Roeckner et al. 1992). Another feature that is evident in both the ECHAM1/LSG model and some other low-resolution uncoupled atmospheric models is the too high values of SLP over Antarctica.

The precipitation rates in the present model (not shown) are smaller in the North Atlantic and North Pacific storm track regions during northern winter than in the climatology of Legates and Willmott (1990). Furthermore, the midlatitude belt with precipitation rates above $4 \mathrm{~mm} \mathrm{day}^{-1}$ in the Southern Hemisphere represented in the observed climatology during DJF is not reproduced in the GCM. The areas of precipitation rates less than $0.5 \mathrm{~mm}$ day $^{-1}$ such as North Africa, East Siberia, and Australia are fairly well simulated in the model. The structure of the tropical precipitation is relatively well captured by the model except in the tropical East Pacific where the Legates and Willmott climatology indicates much higher values. The JJA precipitation rates in the model are overestimated in Southern Hemispheric high latitudes.
The latitude-pressure distribution of the zonally averaged zonal wind is shown in Fig. 11. North of about $45^{\circ} \mathrm{N}$, the DJF zonal circulation in the model is weaker than in the observations. In the Southern Hemisphere, the westerlies in the middle and lower troposphere are underestimated. The winter double jet structure is absent in the model. The errors in the Southern Hemisphere are common in many low-resolution spectral GCMs (Xu et al. 1990).

\section{Variability of the coupled atmosphere-ocean system}

The fact that the gross features of the coupled system averaged over the last $810 \mathrm{yr}$ are acceptable within the range of the ability of the uncoupled ECHAM1 and LSG models in simulating the present-day time-mean climate encourages us to further study the variations in the last 810 yr. The questions concerning the atmospheric and oceanic variations, as addressed in the introduction, are considered in this section.

\section{a. Ocean variability}

To obtain a global description of the oceanic variability, we concentrate now on the questions of where the large oceanic variations are located, what the most dominant modes of the oceanic variations are, and finally to what extent are variations of meridional circulation in the Atlantic related to those in the Pacific and Indian Ocean, and whether meridional circulations influence the horizontal barotropic circulation and vice versa. The first two questions are studied by considering standard deviations of yearly anomalies of different variables and the leading EOFs of these variables. The last two questions are studied by considering the cor- 

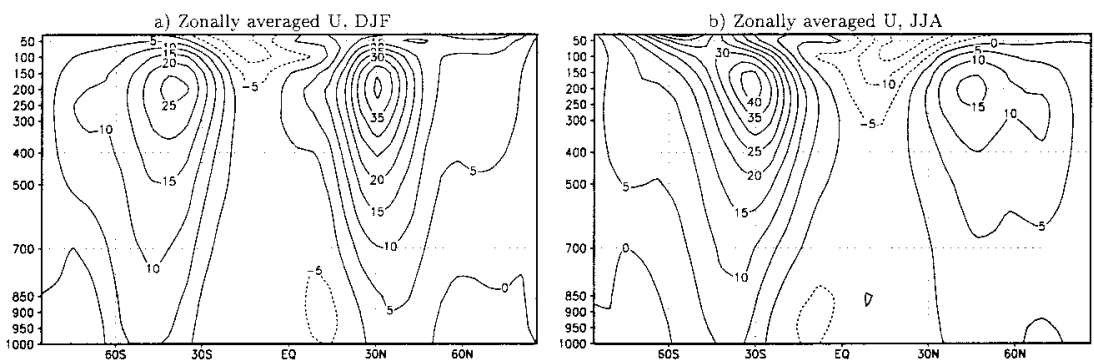

FIG. 11. Latitude-pressure section of zonally averaged zonal wind in northern winter DJF (a) and in northern summer JJA (b) averaged over the last $810 \mathrm{yr}$ of the coupled control run. Contour interval is $5 \mathrm{~m}^{-1} \mathrm{~s}$. Units on $y$ axis are $\mathrm{hPa}$.

relations between the corresponding principal components (PCs).

Figure 12 shows standard deviations of annual anomalies of the horizontal barotropic streamfunction and of the zonally averaged streamfunctions in meridional-vertical cross sections of the Atlantic, the Pacific, and the Indian Ocean. For the horizontal barotropic circulation (Fig. 12a), maximal variations of order of a few Sverdrups are found outside the Tropics, in particular in the North Pacific and the North Atlantic, and at the southern flank of the mean Antarctic Circumpolar Current. For the meridional circulation in the Atlantic (Fig. 12b), the largest variance of about $1 \mathrm{~Sv}$ is found in the center of the overturning circulation at about $2000 \mathrm{~m}$ near $30^{\circ} \mathrm{N}$. In the Pacific (Fig. 12c), besides a secondary variance maximum in the center of the upwelling cell in 2000-m depth near $30^{\circ} \mathrm{S}$, the largest variance is concentrated in the tropical regions of Ekman circulation and in the corresponding upwelling region north of the equator in the $1000-2500 \mathrm{~m}$ depth. The largest variance of the meridional circulation in the Indian Ocean is found south of the equator at about 1000-m depth (Fig. 12d).

The dominant modes are described by the first EOFs of anomalies of horizontal barotropic streamfunction and of zonally averaged meridional streamfunctions in each ocean basin. The data were linearly detrended before the EOF analysis. In contrast to Fig. 12, which characterizes the distribution of the total local variance, the first EOFs in Fig. 13 represent the spatially coherent structures that explain the largest portion of the total covariance. As a consequence, the isolines in Fig. 12 are not streamlines, whereas the isolines in Fig. 13 indicate the trajectories of anomalous flows.

For all considered variables, the first EOFs (Fig. 13) explain one-third to one-half of the corresponding total covariance. The most coherent structure of the horizontal barotropic streamfunction (Fig. 13a) is characterized by a westward (eastward) anomalous circumpolar flow along the Antarctic coast and clockwise (anticlockwise) circulations in the southern Atlantic and southeast of

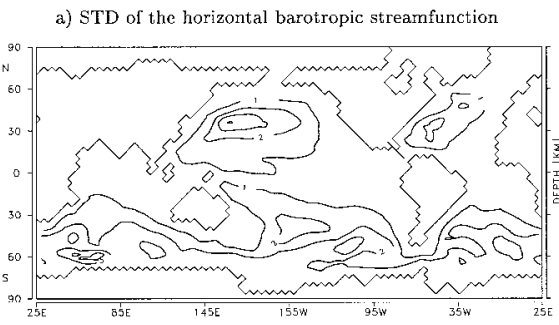

b) STD of the meridional circulation in the Atlantic

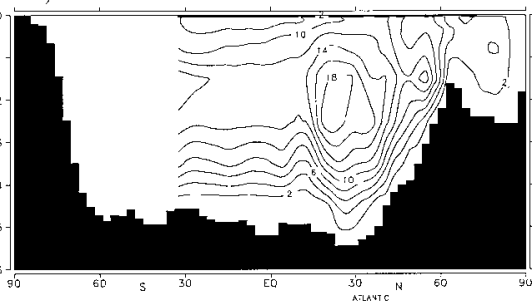

d) STD of the meridional circulation in the Indian Ocean
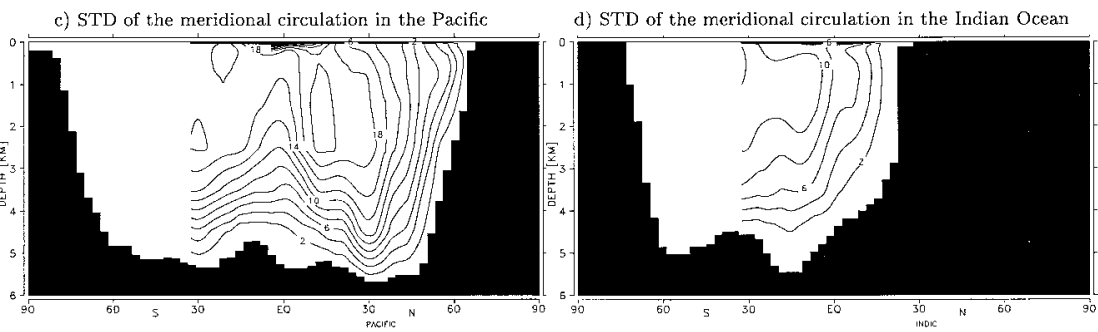

FIG. 12. Standard deviation of annual anomalies of the horizontal barotropic mass transport streamfunction (a) (in Sv), of the streamfunction of the meridional circulation in the Atlantic (b) (in $0.05 \mathrm{~Sv}$ ), in the Pacific (c) (in $0.05 \mathrm{~Sv}$ ), and in the Indian Ocean (d) (in $0.05 \mathrm{~Sv}$ ), as derived from the last $810 \mathrm{yr}$. 


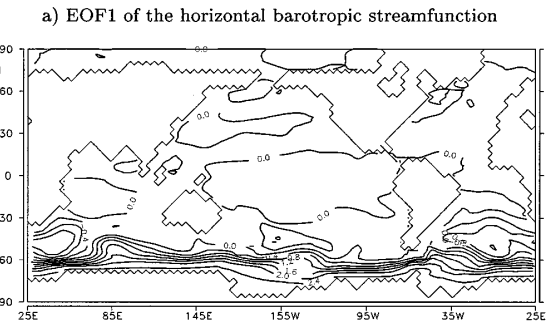

b) EOF1 of the meridional circulation in the Atlantic
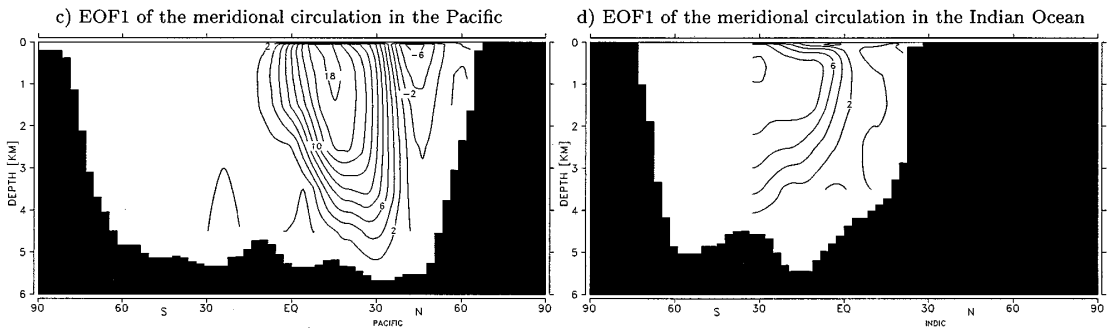

FIG. 13. The first EOFs of linearly detrended annual anomalies of the horizontal barotropic streamfunction (a) (in Sv), of the streamfunction of the meridional circulations (in $0.05 \mathrm{~Sv}$ ) in the Atlantic (b), the Pacific (c), and the Indian Ocean (d), as derived from the last $810 \mathrm{yr}$.

South Africa, and in the southern Pacific, depending on the sign of the EOF coefficient. For the zonally averaged meridional circulations, the most dominant modes in the Atlantic and the Pacific (Figs. 13b,c) describe essentially recirculations within each ocean basin. In contrast to the mean interbasin overturning circulation (Figs. 9bd), which is characterized by strong in- and out-flows across the southern border of the three oceans, the streamlines of anomalous flows shown in Figs. 13b and $13 \mathrm{c}$ are essentially closed north of $30^{\circ} \mathrm{S}$, suggesting closed circulations. The most dominant mode in the Indian Ocean (Fig. 13d) indicates a connection to regions south of $30^{\circ} \mathrm{S}$. It is possible that this circulation cell is also related to a basin-specific recirculation, rather than an interbasin circulation, in the sense that the same anomalous flow from the deep Indian Ocean near $30^{\circ} \mathrm{S}$ returns at the surface near $30^{\circ} \mathrm{S}$. However, since a basinspecific meridional streamfunction is not defined in the open ocean south of about $30^{\circ} \mathrm{S}$, it is impossible to clarify this issue at this stage.

Figure 14 shows the yearly coefficient time series of the corresponding EOFs. A 15-yr running mean is superimposed on each curve. The time series suggest that variations on interdecadal timescale are most pronounced for the Atlantic PC.

Correlations among PCs shown in Fig. 14 suggest that the dominant modes of the Atlantic and Pacific meridional circulations are independent of each other and independent of that of horizontal barotropic motions. An additional analysis using time series of leading atmospheric modes (see section 5b) shows that the latter is strongly correlated to the Southern Hemisphere mode shown in section $5 \mathrm{~b}$, with a correlation of 0.82 . This wind-induced variation has some influence on the first EOF of the meridional circulation in the Indian Ocean.
A correlation of about 0.39 is found for the time series of Figs. 13a and 13d. More detailed studies are required to understand this connection.

The results of the EOF analysis indicate that the most dominant oceanic variations do not take the form of variations of the entire "conveyor belt." The leading modes of the meridional circulations in the Atlantic and Pacific have meridional spatial scales smaller than that of the "conveyor belt" and may describe recirculations within each basin. Such modes are unrelated to each other and are unrelated to the dominant modes of windrelated variations. The wind-related modes can be found not only in the horizontal barotropic streamfunction, but also in the meridional circulation in the Indian Ocean.

\section{b. Atmospheric variability}

This section deals with the question of whether the spatial structures of variations on short timescales are similar to those on long timescales, and whether the atmospheric variations are white on timescales beyond 1 yr. For this purpose, annual time series and time series of 15-yr means are used.

In general, the variance of annual means of a variable is related to the variance of $15-\mathrm{yr}$ means of the same variable. If the annual values of the considered variable are temporally uncorrelated, that is, they represent a white noise time series with no internal memory, standard deviations of annual means and 15-yr means of this variable would satisfy

$$
\frac{\operatorname{Var}(x)^{1 / 2}}{\operatorname{Var}(\bar{x})^{1 / 2}}=\sqrt{N},
$$

where $N$ is the length of time averaging, in our case 15 $\mathrm{yr}, \operatorname{Var}(x)$ is the variance of annual values, and $\operatorname{Var}(\bar{x})$ 

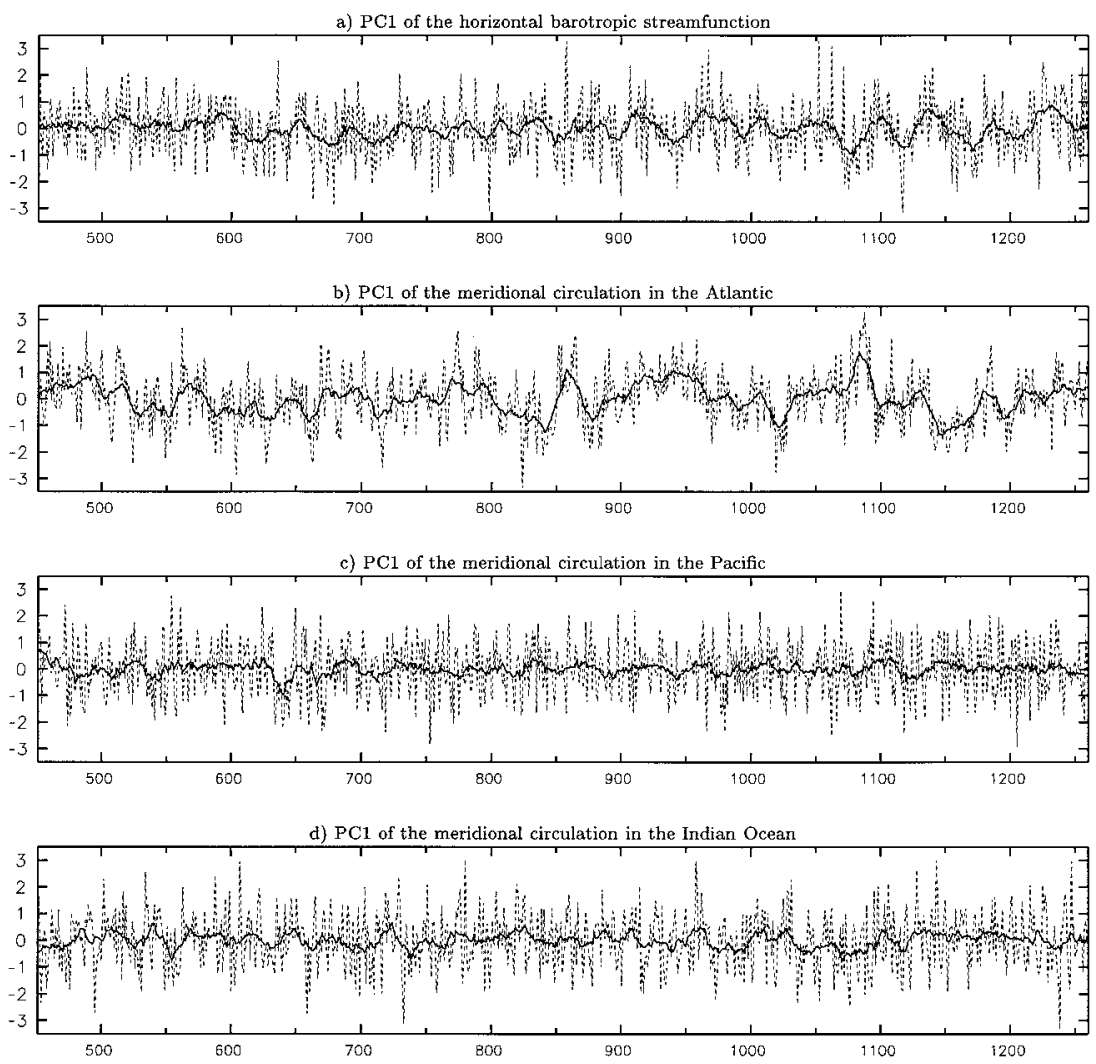

FIG. 14. Normalized time series of the first EOFs of the horizontal barotropic streamfunction (a), of the streamfunction of the meridional circulations in the Atlantic (b), the Pacific (c), and Indian Ocean (d), as derived from the last $810 \mathrm{yr}$ (dashed lines). The solid curves are 15 -yr running means.

is the variance of $N$-year means. If the annual values are not temporally independent, one would obtain a relation similar to (1) but with $N$ being replaced by $N^{\prime}<$ $N$. Here, $N^{\prime}$, also referred to as the equivalent sample size, characterizes the effective amount of independent information in a sample of length $N$. Several procedures for estimating the equivalent sample size $N^{\prime}$ were proposed, for example, by Thiébaux and Zwiers (1984) and by Zwiers and H. von Storch (1995). A detailed discussion of the caveats of the "equivalent sample size" can be found in Zwiers and H. von Storch (1995).

The temporal correlation feature of the considered time series can be characterized by the so-called decorrelation time $\tau_{D}$, defined by

$$
\tau_{D}=\lim _{N \rightarrow \infty} \frac{N}{N^{\prime}} \Delta t .
$$

For a white noise time series, $\tau_{D}=\Delta t$. For a time series generated by a first-order auto-regressive process [AR(1)],

$$
\tau_{D}=\frac{1-\alpha}{1+\alpha} \Delta t
$$

with $\alpha$ being the coefficient of the AR(1) process. In the following, it is assumed that the atmospheric time series can be, to the lowest order, approximated by an $\operatorname{AR}(1)$ process. Following this assumption, $\tau_{D}$ is calculated from (3), by first estimating $\alpha$. In general, the resulting numbers reflect to some (unknown) extent sampling variability. Here, $\tau_{D}$ has therefore only informational value when it is well above the time increment. An extensive discussion about how to interpret the values of $\tau_{D}$ can be found in von Storch (1995).

The answers to the questions addressed at the beginning of this section are indicated by the values of $\operatorname{Var}(x)^{1 / 2} / \operatorname{Var}(\bar{x})^{1 / 2}$ and $\tau_{D}$. If time series at all grid points are white on timescales beyond $1 \mathrm{yr}, \tau_{D}$ would be not much larger than one and the ratio $\operatorname{Var}(x)^{1 / 2} / \operatorname{Var}(\bar{x})^{1 / 2}$ would be about $\sqrt{N}$ at all grid points. However, since the whiteness of local time series does not require frequency independent covariance structures and frequency independent covariance structures do not require white spectra, standard deviations maps and EOFs of yearly and 15-yearly data are calculated to study the frequency dependence of the spatial distribution of the variance and the dominant covariance structure.

Figure 15 shows standard deviations of annual and 15 -yr means of the streamfunction at $300 \mathrm{hPa}$, which 
a) STD of annual PSI300

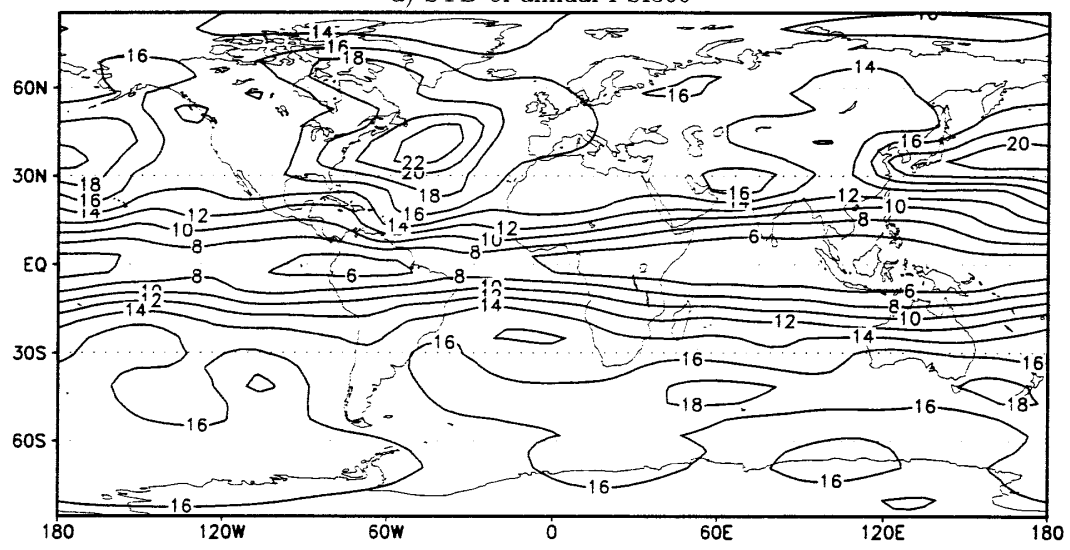

b) STD of 15-year means of PSI300

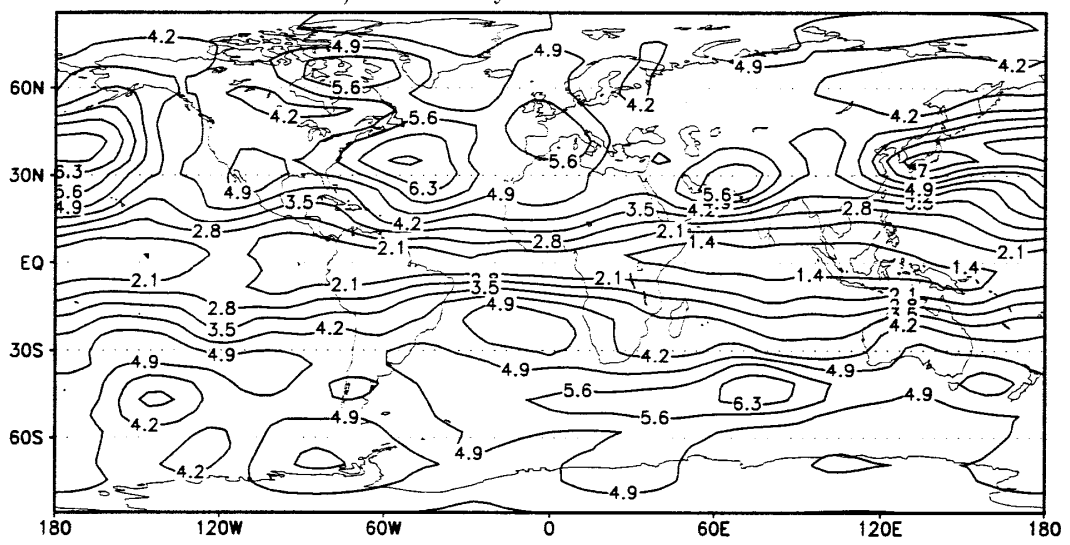

c) Decorrelation time of annual PSI300

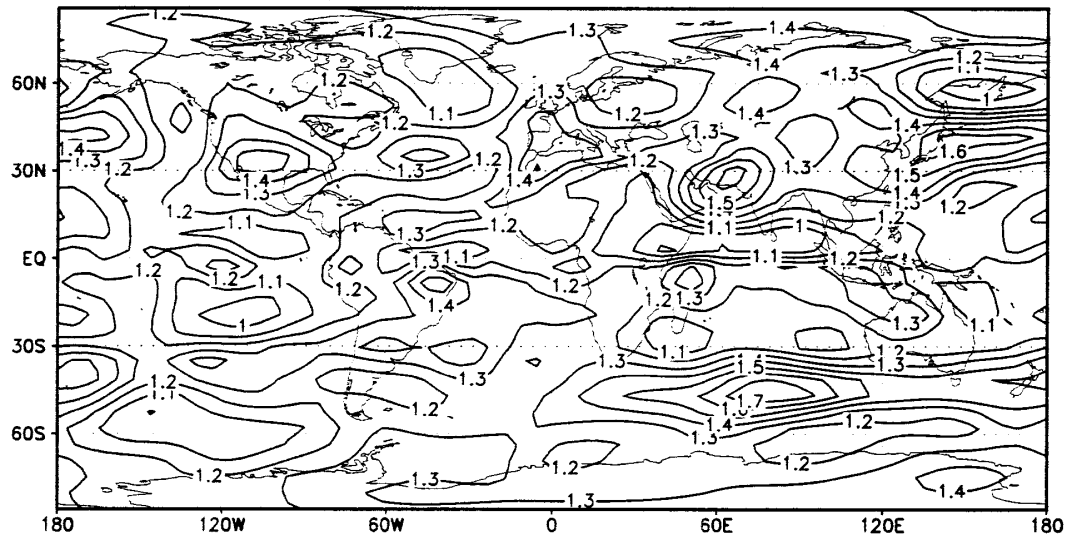

FIG. 15. Standard deviations of 300-hPa streamfunction annual anomalies (a) (contour interval is $2 \cdot 10^{5} \mathrm{~m}^{2} \mathrm{~s}^{-1}$ ) and of 15 -yr means (b) (contour interval is $0.7 \cdot 10^{5} \mathrm{~m}^{2} \mathrm{~s}^{-1}$ ), decorrelation time of annual anomalies (c) (contour interval is $0.1 \mathrm{yr}$ ). Labels in (a) and (b) are multiplied by $10^{-5}$, as derived from the last $810 \mathrm{yr}$.

describes the dynamical state of the upper-troposphere both in midlatitudes and in the Tropics, and its decorrelation time, which is estimated locally from the annual values using Eq. (3). The general structures of the streamfunction variability are similar in both cases (Fig. 15a,b). Maxima of variance are found at midlatitudes over the western North Atlantic and North Pacific as well as at Southern Hemispheric midlatitudes. The Tropics are the regions with low variability.

The ratio of local standard deviation of annual means 

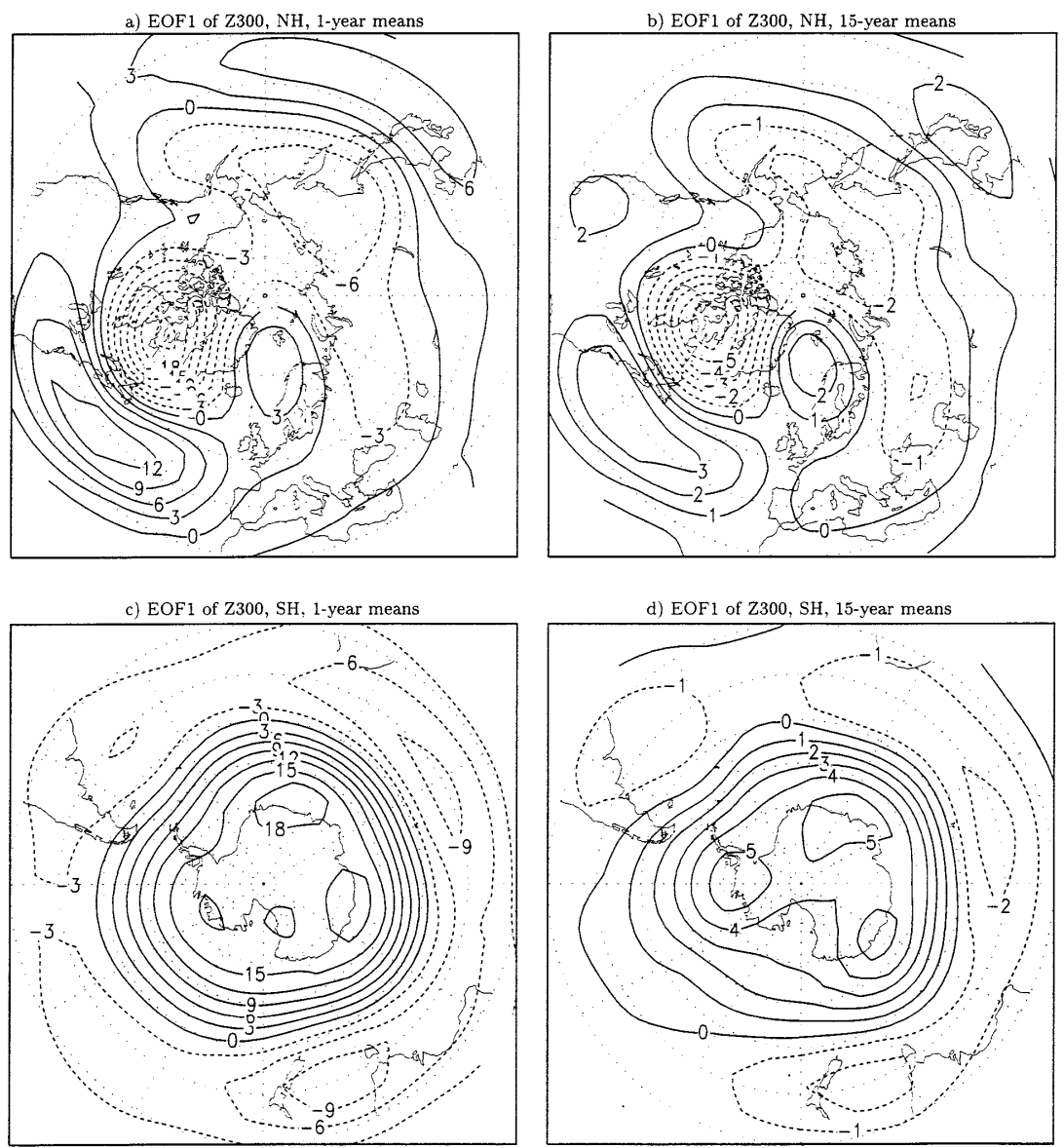

FIG. 16. The first EOFs of 300-hPa geopotential height in the Northern Hemisphere (a), (b) and in the Southern Hemisphere (c), (d), as derived from annual anomalies (left panels; contour interval is $3 \mathrm{gpm}$ ) and 15-yr anomalies (right panels; contour interval is $1 \mathrm{gpm}$ ) of the last $810 \mathrm{yr}$.

of the $300-\mathrm{hPa}$ streamfunction to that of 15 -yr means is close to $\sqrt{15}$ almost everywhere (not shown). The decorrelation time of annual means (Fig. 15c) is about $1 \mathrm{yr}$ in most regions and about $1.5 \mathrm{yr}$ in small areas over the western North Pacific, over the Gulf of Oman, and over the southern Indian Ocean. The results indicate that the streamfunction time series are essentially white on timescales longer than $1 \mathrm{yr}$ at almost all grid points.

The leading EOFs of annual anomalies and 15-yr anomalies in the Northern Hemisphere, Southern Hemisphere, and the Tropics are shown in Figs. 16 and 17. For all considered variables, the spatial structures of the first EOF of annual anomalies are comparable to those of $15-\mathrm{yr}$ anomalies. In the Northern Hemisphere, the first EOFs of both annual and 15-yr anomalies of 300$\mathrm{hPa}$ height, which has essentially the same information in midlatitudes as the streamfunction, are characterized by a dipole structure in the North Atlantic sector and have weak anomalies elsewhere (Figs. 16a,b). The first EOFs of annual and 15-yr means explain 15\% and 18\% of the total variance, respectively. They describe basically the variability of the North Atlantic jet.
In the Southern Hemisphere, the first EOFs of both annual and 15-yr anomalies of height (Figs. 16c,d) reveal a nearly zonally symmetric structure with anomalies at midlatitudes being out-of-phase with those at high latitudes. They explain about $30 \%$ of the total variability of annual and 15-yr anomalies, respectively, and are very well separated from the second EOFs.

For the tropical $300-\mathrm{hPa}$ streamfunction, one has again the situation that the 1-yr and 15-yr first EOFs have the same structure (Fig. 17). They are essentially zonally symmetric and explain about $40 \%$ of the total variance of annual and 15-yr anomalies, respectively.

Both the Southern Hemispheric mode and the tropical mode are also found in the monthly, even daily, observational data (Kang and Lau 1994; Rogers and van Loon 1982; Trenberth and Christy 1985). The Northern Hemispheric mode is comparable to the western Atlantic pattern identified by Wallace and Gutzler (1981) for monthly data in the winter Northern Hemisphere. Further EOF analysis using monthly data of the last $810-\mathrm{yr}$ integration indicates that the dominant patterns in the tropospheric geopotential height and streamfunction remain 
a) EOF1 of PSI300, 1-year means

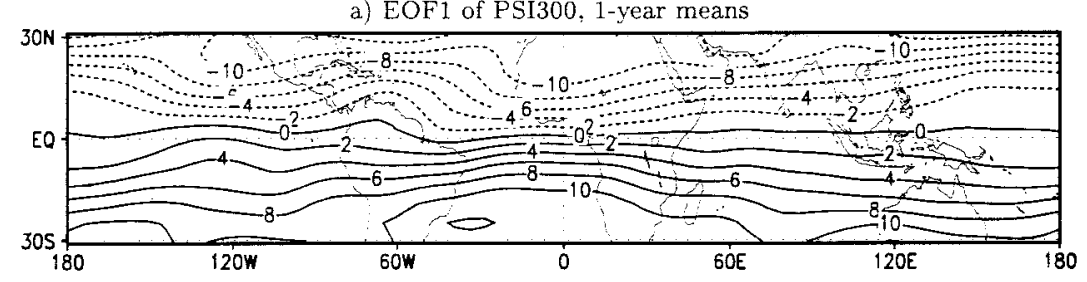

b) EOF1 of PSI300, 15-vear means

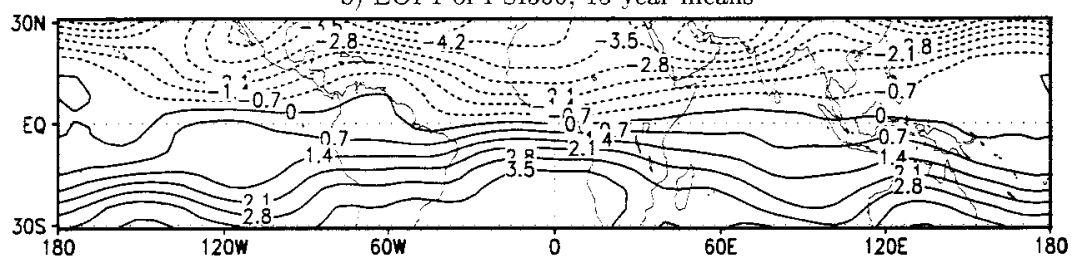

FIG. 17. The first EOFs of the 300-hPa streamfunction in the Tropics, as derived from the annual anomalies (a) (contour interval: $210^{5} \mathrm{~m}^{2} \mathrm{~s}^{-1}$ ) and 15-yr anomalies (b) (contour interval: $0.710^{5} \mathrm{~m}^{2} \mathrm{~s}^{-1}$ ) of the last $810 \mathrm{yr}$. Labels are multiplied by $10^{-5}$.

unchanged, no matter whether the analysis is focused on monthly, yearly, or 15-yearly timescales. The results suggest that the same mechanism operates in the middle and upper troposphere on timescales longer than a month.

In an analysis using the first 325-yr data of the present integration, von Storch (1994) showed that the Southern Hemispheric mode (Figs. 16c,d) and the tropical mode (Fig. 17) are not directly generated by the underlying ocean. On the contrary, the anomalous atmospheric circulation, in particular the Southern Hemispheric mode over the Antarctic Circumpolar region, produces changes in oceanic circulations. Wind-induced anomalies of ocean temperature and current are found in the first two layers of the ocean. There are some indications that these results hold also for the last $810 \mathrm{yr}$. However, further analysis is required to verify this issue.

Using the first $500 \mathrm{yr}$ of the present integration, it was shown by von Storch (1997, manuscript submitted to J. Atmos. Sci.) that among the modes derived from temperature, velocity potential, and streamfunction at various levels, the Southern Hemispheric mode and the tropical mode are the reddest modes (the mode whose time coefficient has the reddest power spectrum) in the ECHAM1/LSG atmosphere with the frequency of the bending point of the power spectra being around (2 months $)^{-1}$ [meaning that the spectral energy increases with decreasing frequency, but has a constant level on frequency smaller than $(2 \text { months })^{-1}$. The results of this paper show that these two modes are also the leading modes in the last $810 \mathrm{yr}$ of the integration, indicating that they are not affected by the drift in the mean state. Furthermore, it suggests that the whiteness of the dominant atmospheric variations on long timescales is at least in the ECHAM1/LSG model, independent on the mean state.

\section{Summary and conclusions}

A description of a 1260-yr integration with the ECHAM1/LSG coupled model is given in this paper. We mainly concentrated on the two types of the timevarying behaviors of the atmosphere-ocean system. One represents the climate drifts and the enhanced initial variability that may be induced by the switch of the fixed air-sea fluxes prior the coupling to the time varying fluxes after the coupling. The other characterizes the typical variability of the coupled system after the initial variations due to the coupling shock have been settled down.

The initial drift is caused, to a large extent, by the imbalances in the globally integrated heat fluxes into the ocean at the beginning of the integration. This imbalance is related to the flux correction term, which has very large upward heat fluxes in the polar regions, in particular along the Antarctic coast. These large and spatially fixed values of heat flux do not match the timevarying distribution of sea ice and cause the drastic growth of global sea ice. The sea ice drift in turn induces a decrease in the temperature of the upper ocean and the atmosphere in both hemispheres. The growth of sea ice also causes the first few layers of the ocean to become more saline. After about $100 \mathrm{yr}$ sea ice volume decreases dramatically in the Southern Hemisphere in the following $300 \mathrm{yr}$, resulting in changes in near-surface temperature as well as in the tropospheric temperature and zonal wind at Southern Hemispheric polar latitudes near $60^{\circ} \mathrm{S}$.

The integrated fluxes of heat and freshwater become quasi-stationary after a few hundred years. The quasistationary near-zero flux of heat generates a quasi-stationary global temperature in the first few layers of the ocean. The negative quasi-stationary flux of freshwater, which is induced by the changed rate of snow accu- 
mulation over Greenland and Antarctica produces a linear trend in salinity in the upper ocean. The evolutions of the temperature and salinity in the deep ocean are not affected by the temporal variations of the globally integrated fluxes during the integration. They are presumably related to the problems that occured during the spinup run of the uncoupled ocean model. The coupling shock resulting from the switch from fixed fluxes prior to the coupling to the time-varying fluxes after the coupling is most apparent in time series of indices of oceanic circulations. The evolution of the global thermohaline state of the ocean seems to be decoupled from that of the dynamical state of the oceanic circulation.

For the oceanic variations, the analysis is focused on the questions of where the large oceanic variations are located, what the dominant modes of the oceanic variations are, and to what extent are variations in different parts of the oceanic circulation related to each other. The results suggest that the largest variations of the horizontal barotropic circulation are located outside the Tropics, in particular in the North Pacific and the North Atlantic, and at the southern flank of the mean position of the Antarctic Circumpolar Current. Large variations of meridional circulations in three ocean basins are located in the intermediate depth. The most dominant mode in the horizontal barotropic streamfunction reveals an anomalous westward (eastward) circumpolar flow together with clockwise (anticlockwise) circulations in the Southern Atlantic and southeast of South Africa and in the Southern Pacific. For the zonally averaged meridional circulation in the Atlantic and the Pacific, the most dominant modes describe recirculations within each basin. These two modes are independent of each other and independent of those of the windrelated variations.

For the atmospheric variations, the dominant modes, the North Atlantic mode in the Northern Hemisphere, and the nearly zonally symmetric modes in the tropical and Southern Hemisphere, reveal the same spatial structures on both the short ( $1 \mathrm{yr})$ and long (15 yr) timescales. In terms of 300-hPa geopotential height and streamfunction, the analysis of the decorrelation time indicates that the atmosphere is essentially white on timescales longer than $1 \mathrm{yr}$.

Acknowledgments. It is a pleasure for us to thank Ernst Maier-Reimer and Uwe Mikolajewicz for helpful discussions concerning the oceanic circulation and Nanne Weber for discussion concerning flux correction over sea ice areas. Thanks also to Ron Stouffer and the other anonymous reviewer for their helpful comments. Special thanks to Nathalie Sennéchael and Claude Frankignoul, who helped us to discover an error in the computation of Fig. 13. V. Kharin, J.-S. von Storch, and H. von Storch did most of their contribution while at the Max-Planck Institute for Meteorology in Hamburg. Financial support was given by EU-Grant 275 ("Millennia").

\section{REFERENCES}

Bakan, S., and Coauthors, 1991: Climate response to smoke from the burning oil wells in Kuwait. Nature, 351, 367-371.

Blackmon, M. L., 1976: A climatological spectral study of the 500-mb geopotential height of the Northern Hemisphere. J. Atmos. Sci., 33, 1607-1623.

-, Y. H. Lee, and J. M. Wallace, 1984: Horizontal structure of $500-\mathrm{mb}$ height fluctuations with long, intermediate and short time scales. J. Atmos. Sci., 41, 961-979.

Cubasch, U., K. Hasselmann, H. Höck, E. Maier-Reimer, U. Mikolajewicz, B. D. Santer, and R. Sausen, 1992: Time-dependent greenhouse warming computations with a coupled ocean-atmosphere model. Climate Dyn., 8, 55-69.

— B. D. Santer, A. Hellbach, G. Hegerl, H. Höck, E. Maier-Reimer, U. Mikolajewicz, A. Stössel, and R. Voss, 1994: Monte Carlo climate change forecasts with a global coupled ocean-atmosphere model. Climate Dyn., 10, 1-19.

—, G. Hegerl, A. Hellbach, H. Höck, U. Mikolajewicz, B. D. Santer, and R. Voss, 1995: A climate change simulation starting 1935. Climate Dyn., 11, 71-84.

Delworth, T., S. Manabe, and R. Stouffer, 1993: Interdecadal variability of the thermohaline circulation in a coupled ocean-atmosphere model. J. Climate, 6, 1993-2011.

Drijfhout, S., C. Heinze, M. Latif, and E. Maier-Reimer, 1996: Mean circulation and internal variability in an ocean primitive equation model. J. Phys. Oceanogr., 26, 559-580.

Gates, L., U. Cubasch, G. A. Meehl, J. F. B. Mitchell, and R. J. Stouffer, 1993: An intercomparison of the control climates simulated by coupled atmosphere-ocean general circulation models. SGCCM, WCRP-82, WMO/TD No. 574, 51 pp. [Available from World Meteorological Organization, Geneva CP2300, Switzerland.]

Gates, W. L., A. Henderson-Sellers, G. J. Boer, C. F. Folland, A. Kitoh, B. J. McAvaney, F. Semazzi, N. Smith, A. J. Weaver, and Q.-C. Zeng, 1996: Climate models: Evaluation. The IPCC Second Scientific Assessment of Climate Change, J. T. Houghton, L. G. Meiro, B. A. Callender, N. Harris, A. Kattenberg, and K. Maskell, Eds., Cambridge University Press, 229-284.

Hasselmann, K., 1976: Stochastic climate models. Part I: Theory. Tellus, 28, 473-485.

Hegerl, G. C., H. von Storch, K. Hasselmann, B. D. Santer, U. Cubasch, and P. D. Jones, 1996: Detecting anthropogenic climate change with an optimal fingerprint method. J. Climate, 9, 22812306.

Hellerman, S., and M. Rosenstein, 1983: Normal monthly wind stress over the World Ocean with error estimates. J. Phys. Oceanogr., 13, 1093-1104.

IPCC, 1992: Climate Change 1992. The Supplementary Report of the IPCC Scientific Assessment. J. T. Houghton, B. T. Callendar, and S. K. Varney, Eds., University Press, 200 pp.

Kang, I.-K., and K.-M. Lau, 1994: Principal modes of atmospheric circulation anomalies associated with global angular momentum fluctuations. J. Atmos. Sci., 51, 1194-1205.

Kim, K. Y., G. R. North, and G. C. Hegerl, 1996: Comparisons of the second-moment statistics of climate models. J. Climate, 9, 2204-2221.

Legates, D. R., and C. J. Willmott, 1990: Mean seasonal and spatial variability in gauge-corrected global precipitation. Int. J. Climatol., 10, 111-127.

Levitus, S., 1982: Climatology atlas of the World Ocean. NOAA Prof. Paper 13, U.S. Govt. Printing Office, 173 pp.

Maier-Reimer, E., and U. Mikolajewicz, 1991: The Hamburg large scale geostrophic ocean general circulation model. DKRZ Tech. Rep. 3, 34 pp. [Available from DKRZ, Bundesstrasse 55, 20146 Hamburg, Germany.]

— - _ , and K. Hasselmann, 1993: Mean circulation of the Hamburg LSG OGCM and its sensitivity to the thermohaline surface forcing. J. Phys. Oceanogr., 23, 731-757.

Manabe, S., and R. J. Stouffer, 1996: Low-frequency variability of 
surface air temperature in a 1000-year integration of a coupled ocean-land surface model. J. Climate, 9, 376-393.

Mikolajewicz, U., and E. Maier-Reimer, 1990: Internal secular variability in an ocean general circulation model. Climate Dyn., 5, $145-156$.

Robertson, A., 1996: Interdecadal variability over the North Pacific in a coupled ocean-atmosphere general circulation model. Climate Dyn., 12, 227-241.

Roeckner, E., and Coauthors, 1992: Simulation of the present-day climate with the ECHAM model: Impact of model physics and resolution. Max-Planck-Institut für Meteorologie Rep. 93, 172 pp.[Available from DKRZ, Bundesstrasse 55, 20146 Hamburg, Germany.]

Rogers, J. C., and H. van Loon, 1982: Spatial variability of sea level pressure and 500-mb height anomalies over the Southern Hemisphere. Mon. Wea. Rev., 110, 1375-1392.

Santer, B. D., K. E. Taylor, J. E. Penner, T. M. L. Wigley, U. Cubasch, and P. D. Jones, 1995: Towards the detection and attribution of an anthropogenic effect on climate. Climate Dyn., 12, 77-100.

, T. M. L. Wigley, T. P. Barnett, and E. Anyamba, 1996: Detection of climate change and attribution of causes. The IPCC Second Scientific Assessment of Climate Change, J. T. Houghton, L. G. Meiro, B. A. Callender, N. Harris, A. Kattenberg, and K. Maskell, Eds., Cambridge University Press, 407-444.

Sausen, R., K. Barthels, and K. Hasselmann, 1988: Coupled oceanatmosphere models with flux correction. Climate Dyn., 2, 154163.

Tett, S. F. B., T. C. Johns, and J. F. B. Mitchell, 1997: Global and regional variability in a coupled AOGCM. Climate Dyn., in press.

Thiébaux, H. J., and F. W. Zwiers, 1984: The interpretation and estimation of effective sample size. J. Climate Appl. Meteor., 23, $800-811$
Trenberth, K. E., and J. R. Christy, 1985: Global fluctuations in the distribution of atmospheric mass. J. Geophys. Res., 90 (D5), 8042-8052.

Untersteiner, N., 1984: The cryosphere. The Global Climate, J. T. Houghton, Ed., Cambridge University Press, 121-140.

von Storch, H., 1994: Interdecadal variability in a global coupled model. Tellus, 46A, 419-432.

_ 1995: Misuses of statistical analysis in climate research. Analysis of Climate Variability; Applications of Statistical Techniques, $\mathrm{H}$. von Storch and A. Navarra, Eds., Springer Verlag, $11-26$.

Wallace, J. M., and D. S. Gutzler, 1981: Teleconnections in the geopotential height field during the Northern Hemisphere winter. Mon. Wea. Rev., 109, 784-812.

Whitworth, T., and R. G. Peterson, 1985: Volume transport of the Antarctic circumpolar current from bottom pressure measurements. J. Phys. Oceanogr., 15, 810-816.

Woodruff, S. D., R. J. Slutz, R. L. Jenne, and P. M. Steurer, 1987: A Comprehensive Ocean-Atmosphere Data Set. Bull. Amer. Meteor. Soc., 68, 1239-1250.

Xu, J.-S., H. von Storch, and H. van Loon, 1990: The performance of four spectral GCMs in the Southern Hemisphere: The January and July climatology and the semiannual wave. J. Climate, 3, 53-70.

Yin, F. L., and E. S. Sarachik, 1995: Interdecadal thermohaline oscillations in a sector ocean general circulation model: Advective and convective processes. J. Phys. Oceanogr., 25, 2465-2484.

Zorita, E., and C. Frankignoul, 1997: Modes of North Atlantic decadal variability in the ECHAM1/LSG coupled ocean-atmosphere general circulation model. J. Climate, 10, 183-200.

Zwiers, F. W., and H. von Storch, 1995: Taking serial correlation into account in tests of the mean. J. Climate, 8, 336-351. 